\title{
Quality Assurance of Surface Wind Observations from Automated Weather Stations
}

\author{
PEDRO A. JimÉNEZ \\ Departamento de Astrofísica y Ciencias de la Atmósfera, Universidad Complutense de Madrid, and División de \\ Energías Renovables, CIEMAT, Madrid, Spain \\ J. FidEL GONZÁLEZ-ROUCO \\ Departamento de Astrofísica y Ciencias de la Atmósfera, Universidad Complutense de Madrid, Madrid, Spain \\ JORGE NAVARRO \\ División de Energías Renovables, CIEMAT, Madrid, Spain \\ JUAN P. MONTÁVEZ \\ Departamento de Física, Universidad de Murcia, Murcia, Spain \\ Elena García-Bustamante \\ Departamento de Astrofísica y Ciencias de la Atmósfera, Universidad Complutense de Madrid, and División de \\ Energías Renovables, CIEMAT, Madrid, Spain
}

(Manuscript received 9 October 2009, in final form 18 February 2010)

\begin{abstract}
Meteorological data of good quality are important for understanding both global and regional climates. In this respect, great efforts have been made to evaluate temperature- and precipitation-related records. This study summarizes the evaluations made to date of the quality of wind speed and direction records acquired at 41 automated weather stations in the northeast of the Iberian Peninsula. Observations were acquired from 1992 to 2005 at a temporal resolution of 10 and $30 \mathrm{~min}$. A quality assurance system was imposed to screen the records for 1) manipulation errors associated with storage and management of the data, 2) consistency limits to ensure that observations are within their natural limits of variation, and 3) temporal consistency to assess abnormally low/high variations in the individual time series. In addition, the most important biases of the dataset are analyzed and corrected wherever possible. A total of $1.8 \%$ wind speed and $3.7 \%$ wind direction records was assumed invalid, pointing to specific problems in wind measurement. The study not only tries to contribute to the science with the creation of a wind dataset of improved quality, but it also reports on potential errors that could be present in other wind datasets.
\end{abstract}

\section{Introduction}

In recent years, there has been increasing demand for high-quality wind observations for a wide range of applications: evaluation of wind energy resources, transport and dispersion of pollutants within the frame of air quality studies, the analysis of extreme wind events by insurance

Corresponding author address: Pedro A. Jiménez, Facultad de Ciencias Físicas, Universidad Complutense de Madrid, Avenida Complutense s/n, 28040 Madrid, Spain.

E-mail: pedro.jimenez@fis.ucm.es. companies or for the design of buildings and structures, etc. Despite this necessity, data depuration processes that specifically deal with wind-related variables are scarce (DeGaetano 1997, 1998; Graybeal 2006). Our understanding of the potential errors that are latent in climatic wind datasets is therefore very limited and hampers the creation of the high-quality datasets demanded.

According to Gandin (1988), the errors associated with meteorological records can be classified into three main groups: random, systematic, and rough errors. Random errors are intrinsic to the measurement definition, an approximation of the real atmospheric state, and so are 
unavoidable. Systematic errors are associated with a more or less persistent factor that introduces a certain bias in the reported values. Biases can be produced by any practice that causes a systematic deviation from the true observation. For instance, this can be the result of a recalibration of the recording instrument, changes in exposure or type of the sensor, changes in the observing time, etc. (e.g., Karl et al. 1986; Parker et al. 2000; Pielke et al. 2007a,b; Thompson et al. 2008). The techniques developed to identify and correct these biases in time series are known as homogeneity adjustments (Alexanderson 1986; Karl and Williams 1987; Peterson et al. 1998a). Rough errors are associated with a malfunctioning of the sensor or mistakes introduced during data processing, transmission, reception, or storage. Recognition and suppression of this third type of erroneous record are the objectives of any quality control (QC) process (Gandin 1988).

The identification and correction of systematic errors (or biases) and the suppression of rough errors from the climatic datasets are tedious and time-consuming tasks known as quality assurance (QA). Usually, QC and QA are used synonymously, but they are two different processes. The aim of both procedures is to ensure the quality of the data, but the former consists of the routine procedures performed during the acquisition of the records, whereas the latter applies to a dataset that already exists. To optimize the use of the resources required in a QA process, it is particularly important to understand the routine observational activities as well as the sporadic incidents that may have affected the acquisition of measurements. This information is known as metadata (WMO 2008), and it facilitates the identification of suspicious observations through a specific design of the procedures applied to assess the veracity of the records.

Surface meteorological observations can be acquired either manually or automatically from weather stations. The first atmospheric records available for climatic research came from manually controlled stations. Temperature and precipitation have been, by far, the most studied variables, and therefore the systematic errors associated with their measurement are those best understood (e.g., Karl et al. 1989; Vincent et al. 2002; Wijngaard et al. 2003; Brunet et al. 2006). The main focus, to detect rough errors in manually acquired records, was outlier detection (Filippov 1968; Grant and Leavenworth 1972; Eischeid et al. 1995; Peterson et al. 1998b; González-Rouco et al. 2001) but, recently, more sophisticated procedures have been investigated to deal with other kinds of problems (Reek et al. 1992; Kunkel et al. 1998; Kunkel et al. 2005). The current research is mainly focused on comparing the performance of different approaches to identify rough errors (Hubbard et al. 2005, 2007; You et al. 2007; Durre et al. 2008). The knowledge gained through the correction of errors associated with temperature and precipitation variables has recently favored the correction of errors associated with other manually acquired meteorological variables, such as surface wind, pressure, or humidity (e.g., Graybeal et al. 2004a,b; Feng et al. 2004; Wan et al. 2007). DeGaetano (1997) developed a complex QC for hourly wind records using measurements obtained manually during almost 40 years at 41 stations in the eastern United States. The small percentage of the records considered suspicious indicated a good quality of the data, but the possibility that other potential errors could still be present on the dataset could not be ruled out. In a subsequent study (DeGaetano 1998), the author went further by analyzing biases in the dataset, finding a tendency to include even records, rounding problems, and a distinct treatment of calms, depending on the institution that maintained the weather station. Graybeal (2006) analyzed the relationship between extreme wind variables and the daily-mean wind speed to establish a relationship that would be helpful in evaluating the quality of the extreme wind records.

The introduction of automatic weather stations has allowed the increased temporal resolution of sampling. In addition, observations are taken at regular time intervals through the day, thus eliminating some biases in the manual observations associated with changes in the timing of observation (Wu et al. 2005). However, the new automatic protocols have introduced new types of systematic and rough errors that are still poorly understood. For instance, Wade (1987) identified biases introduced in the wind speed records due to obstacles in the vicinity of the station as well as biases in the wind direction as a consequence of the incorrect placement of the wind vane offset. However, errors associated with wind records acquired at automated weather stations have only been analyzed as part of more ambitious programs that involved the correction of errors in other meteorological variables, without going into depth concerning the specific problems related with this type of measurement (e.g., Wade 1987; Meek and Hatfield 1994; Shafer et al. 2000).

The present work summarizes the QA applied to wind observations taken at 41 automatic weather stations. First, the QA procedure screens records to detect rough errors to subsequently analyze, and correct if possible, the most important biases of the dataset. The observations available were collected over a $13-\mathrm{yr}$ period at a temporal resolution of 10 or $30 \mathrm{~min}$. To our knowledge, no previous studies have specifically focused on improving the quality of wind records acquired from automated weather stations at such high frequencies and during such an extended period. The QC systems applied to the data 
TABLE 1. Code of the meteorological station as in Fig. 1: name, latitude, longitude, elevation, sensor height above ground level, and installation date.

\begin{tabular}{|c|c|c|c|c|c|c|}
\hline No. & Name & Lat $\left(^{\circ}\right)$ & Lon $\left(^{\circ}\right)$ & Elev (m) & Height (m) & Installation date \\
\hline 1 & Aguilar de Codés & 42.614 & -2.394 & 731 & 10 & 1 Mar 1992 \\
\hline 2 & Aoiz-Agoitz & 42.792 & -1.369 & 530 & 10 & 1 Mar 1992 \\
\hline 3 & Aralar & 42.954 & -1.963 & 1393 & 10 & 1 Mar 1992 \\
\hline 4 & Arangoiti & 42.646 & -1.194 & 1353 & 10 & 1 Jan 1992 \\
\hline 5 & Arazuri & 42.801 & -1.702 & 396 & 2 & 4 Feb 2000 \\
\hline 6 & Bardenas-barranco salado & 42.265 & -1.654 & 300 & 2 & 1 Mar 1998 \\
\hline 7 & Bardenas-Loma negra & 42.071 & -1.375 & 646 & 10 & 1 Mar 1992 \\
\hline 8 & Bardenas-Nstra Sra. del Yugo & 42.206 & -1.582 & 472 & 10 & 1 Jan 1992 \\
\hline 9 & Bardenas-polígono de tiro & 42.200 & -1.473 & 295 & 10 & 1 May 1997 \\
\hline 10 & Beortegi & 42.796 & -1.434 & 580 & 10 & 1 May 1997 \\
\hline 11 & Cadreita-Riegos & 42.209 & -1.717 & 268 & 2 & 1 Mar 1998 \\
\hline 12 & Cadreita-INM & 42.208 & -1.710 & 268 & 10 & 1 Mar 1992 \\
\hline 13 & Carcastillo & 42.372 & -1.463 & 340 & 10 & 1 Mar 1992 \\
\hline 14 & Carrascal & 42.683 & -1.660 & 560 & 10 & 1 Jan 1992 \\
\hline 15 & Doneztebe & 43.132 & -1.660 & 138 & 10 & 1 Jun 1999 \\
\hline 16 & Perdón & 42.733 & -1.709 & 1024 & 10 & 1 Jan 1992 \\
\hline 17 & Estella-Lizarra & 42.676 & -2.028 & 480 & 10 & 1 Jan 1992 \\
\hline 18 & Etxarri-Aranatz & 42.910 & -2.057 & 507 & 10 & 1 Jan 1992 \\
\hline 19 & Getadar & 42.605 & -1.457 & 710 & 10 & 1 May 2000 \\
\hline 20 & Gorramendi & 43.220 & -1.432 & 1071 & 10 & 1 May 1992 \\
\hline 21 & Ilundain & 42.777 & -1.529 & 542 & 10 & 1 Mar 1992 \\
\hline 22 & Isaba & 42.864 & -0.923 & 843 & 10 & 1 Jul 1992 \\
\hline 23 & Lekaroz & 43.144 & -1.545 & 182 & 10 & 1 Mar 1992 \\
\hline 24 & Lumbier-Ilumberri & 42.668 & -1.275 & 484 & 2 & 5 May 2000 \\
\hline 25 & Montes del Cierzo & 42.133 & -1.652 & 310 & 10 & 1 Jul 1998 \\
\hline 26 & Oskotz & 42.956 & -1.756 & 562 & 10 & 1 Mar 1999 \\
\hline 27 & Pamplona-Larrabide & 42.810 & -1.638 & 450 & 10 & 1 Jan 1997 \\
\hline 28 & Pamplona-Noain & 42.769 & -1.639 & 461 & 10 & 1 Apr 1992 \\
\hline 29 & Remendia-Salazar & 42.879 & -1.184 & 1047 & 10 & 1 Oct 2001 \\
\hline 30 & Roncesvalles-Orreaga & 43.009 & -1.325 & 940 & 10 & 1 Mar 1992 \\
\hline 31 & Sartaguda-Riegos & 42.363 & -2.050 & 310 & 2 & 1 Mar 1998 \\
\hline 32 & Sartaguda-INM & 42.366 & -2.051 & 310 & 10 & 1 Mar 1992 \\
\hline 33 & Tafalla & 42.522 & -1.676 & 415 & 10 & 1 Mar 1992 \\
\hline 34 & Traibuenas & 42.363 & -1.614 & 312 & 2 & 14 Apr 1999 \\
\hline 35 & Trinidad de Iturgoien & 42.819 & -1.975 & 1222 & 10 & 1 Jan 1992 \\
\hline 36 & Tudela & 42.057 & -1.608 & 295 & 10 & 1 Mar 1992 \\
\hline 37 & Ujué & 42.513 & -1.510 & 826 & 10 & 1 Jan 1992 \\
\hline 38 & Urbasa & 42.853 & -2.175 & 890 & 10 & 1 Oct 2001 \\
\hline 39 & Valdega & 42.657 & -2.172 & 469 & 2 & 1 May 2001 \\
\hline 40 & Villanueva del Yerri & 42.736 & -1.949 & 498 & 10 & 1 Jan 1998 \\
\hline 41 & Yesa & 42.618 & -1.190 & 489 & 10 & 1 Mar 1992 \\
\hline
\end{tabular}

during the acquisition period were very limited or nonexistent, and so the potential number of erroneous records could be high. In this sense, the study does not only try to provide an improved wind dataset, but it also discusses potential errors that could be present in other wind datasets.

The following section describes the observational dataset. Sections 3 and 4 describe the methodologies of the QA process used to deal with rough and systematic errors, respectively. The spatiotemporal distribution of the records invalidated by the part of the QA dealing with rough errors is presented in section 5 , and the modifications introduced by the correction of biases are discussed in section 6. The impact of the corrections is discussed in section 7, and the conclusions are given in section 8 .

\section{Observational wind data}

The wind speed and direction measurements were collected from 1 January 1992 to 7 October 2005 at 41 automatic weather stations (Table 1) over the Comunidad Foral de Navarra (CFN), a complex terrain region located in northeastern Spain (Fig. 1). The stations are managed by three different institutions: Gobierno de Navarra (GN, circles in Fig. 1), Agencia Estatal de Meteorología 


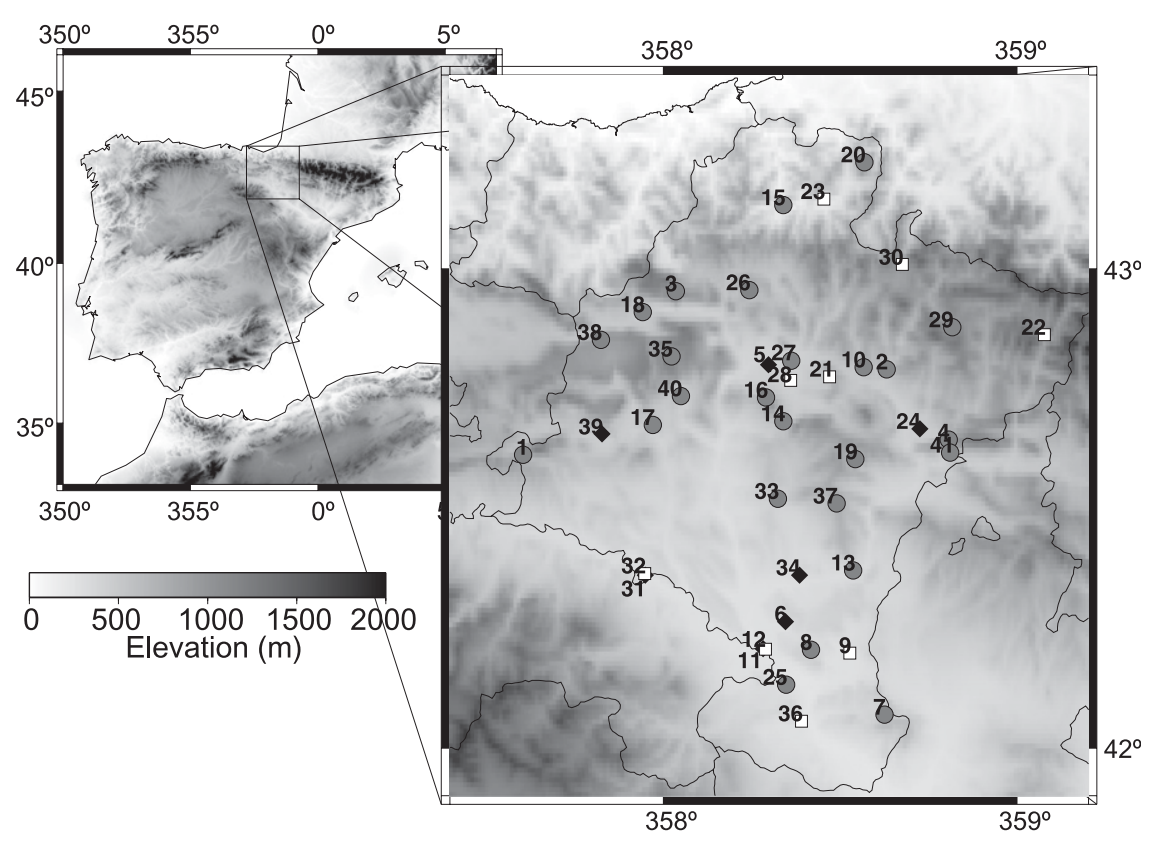

FIG. 1. Location of the CFN within the Iberian Peninsula. Shading represents the elevation and (right) circles, squares, and diamonds represent the location of the meteorological stations from GN, AEMET, and RN, respectively. The numbers associated to each location can be used to obtain more specific details of the meteorological stations in Table 1.

(AEMET, squares in Fig. 1), and Riegos de Navarra (RN, diamonds in Fig. 1). The majority of the stations are located in sites following the World Meteorological Organization (WMO) standards, but some of the sites do not satisfy these standards. For instance, PamplonaLarrabide and Estella-Lizarra are located at the top of buildings. The observations of the GN stations were acquired either via modem, with three calls every day, or in real time via radio trunking. GN received the observations from AEMET and RN by a daily FTP, and it is responsible for storing and maintaining the whole dataset. Metadata concerning maintenance operations of the weather stations is very limited. Only information on the operations performed to the wind sensors of the GN stations from 2000 to the end of 2002 was provided.

All stations recorded the wind speed in meters per second and the wind direction in degrees with respect to north. However, two different wind sensors were used to acquire observations. The GN and RN wind sensors are able to measure wind speeds of up to $60 \mathrm{~m} \mathrm{~s}^{-1}$ and present a cut-in wind speed of $1.0 \mathrm{~m} \mathrm{~s}^{-1}$, whereas the anemometer employed by AEMET is able to register a maximum wind speed of $50 \mathrm{~m} \mathrm{~s}^{-1}$ and presents a cutin wind speed of $0.3 \mathrm{~m} \mathrm{~s}^{-1}$. The temporal resolution of the records is $10 \mathrm{~min}$ except for the stations managed by RN, which after March 2004 provided averages of the wind observations every $30 \mathrm{~min}$.
Another source of discrepancy between the various datasets is the treatment of calm. Some datasets assign the zero wind direction value to zero wind speed records, keeping $360^{\circ}$ for northern winds. Other datasets treat the wind speed and wind direction measurements independently with no special attention to calm records. The original wind dataset facilitated by GN contained both treatments of calm records. This was due to the different criteria selected by each institution as well as changes in the criteria adopted with time. To avoid this bias in the dataset, it was decided to adopt the same calm criterion for all the records. Because there are periods with zero wind direction values for calms winds, and their transformation to regular wind direction values is not easy, the criterion that assigns zero wind direction values to zero wind speed records was finally adopted.

\section{QA methodologies: Rough errors}

The QA applied herein consists of a sequential application of several checks to identify questionable data in both a wind speed and wind direction time series. Tests are arranged in a logical sequence to effectively assess the reliability of observations with regard to the kind of problem in hand. Some checks in the QA directly flagged observations as invalid, whereas others reported questionable observations for later inspection, introducing a certain degree of subjectivity in the QA. 


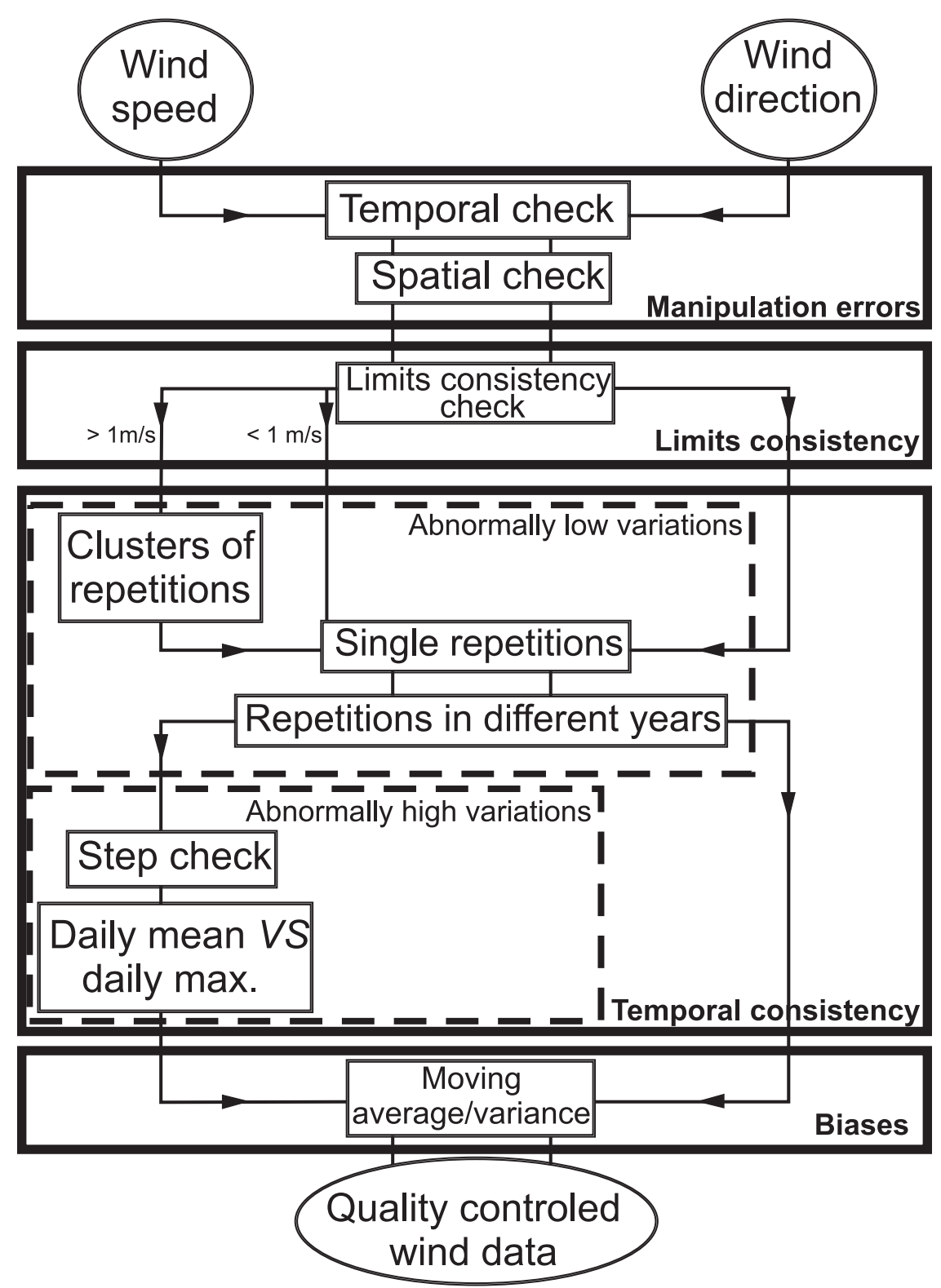

FIG. 2. Diagram of the QA. The name of each check applied to the data is represented within a thin rectangle. The four rectangles in bold comprise the checks associated with manipulation errors, limits consistency, temporal consistency, and biases. The third rectangle contains two additional rectangles (dashed) that comprise the checks that deal with abnormally low and high variations in the records.

This undesirable characteristic was mitigated by designing the checks in such a way that they minimized the number of periods that needed to be manually inspected. No attempt was made to replace the missing values introduced in the time series.

The flow diagram of the QA is shown in Fig. 2. The wind speed and wind direction data are assessed independently, although most of the steps (those depicted in the central column of the QA diagram) are common for both variables. The tests dealing with rough errors are subdivided into three main groups: 1) checks to detect manipulation errors associated with the storage and maintenance of a dataset, 2) limits of consistency checks to remove records outside the allowable range of variation, and 3) checks to ensure the temporal consistency of the individual time series by assessing records with abnormally low/high variations. The possibility of including a fourth step to ensure spatial consistency between 
observations acquired at different locations (e.g., Kunkel et al. 1998; Shafer et al. 2000) was considered. However, the stations are not close enough to ensure similar conditions within the averaged periods (10 $\mathrm{min})$, and thus a direct implementation of this kind of check could not have been straightforward. Future research in this direction would help to increase the performance of the present QA.

The following sections describe the different checks of each group.

\section{a. Manipulation errors}

First, wind speed and direction observations are screened to detect manipulation errors (Fig. 2). These types of errors are associated with the management and storage of data. The checks applied herein look for a temporal or spatial misplacement of observations that might coincide with other observations in a given time series or with measurements from other stations.

The temporal assessment attempts to detect periods with repeated observations within the measurements at a single station. It requires the choice of a time step to discretize the time series to define the periods to check. The length of the period used to discretize the time series should be the one at which the data are received and stored. In this particular wind dataset, the frequency in the data reception was every 8 and $24 \mathrm{~h}$ (see section 2), and therefore these were the time steps selected. Thus, each period was compared against the rest, looking for coincident measurements, and verifying that their variances were higher than zero. Hence, the comparisons are not restricted to consecutive periods. The dates of the periods with repeated records and the code of the station were noted for a subsequent inspection. One of these cases can be observed in Fig. 3a. The wind speed observations from station Lekaroz show several days with a strong diurnal cycle due to natural variability; however, there are identical measurements for the first and the second day of May. These days also present coincident measurements in the wind direction time series (not shown), suggesting the incorrect temporal assignment of observations from one day to the other. Because this type of coincidence is very unlikely to happen, both wind speed and wind direction measurements of the two days were eliminated and flagged as missing values.

The spatial check for manipulation errors allows coincident measurements between stations to be detected. It reports the dates of the periods with repeated records and the code of the stations if they present the same measurements for more than $8 \mathrm{~h}$, which is the shortest period in the data acquisition, and if their variance is higher than zero. The comparison is not restricted to 8-h periods with the same date, but rather each period from

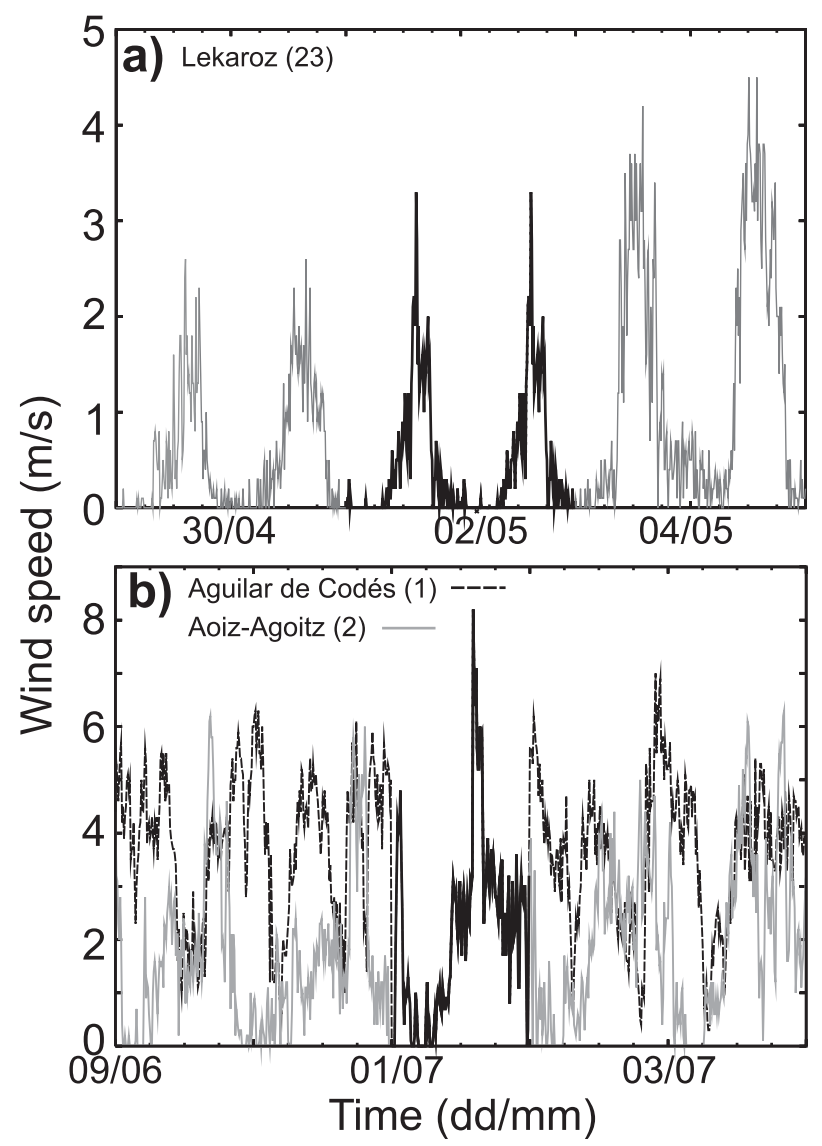

FIG. 3. Examples of wind speed records in two cases of identical observations. (a) Records from a period observed at Lekaroz associated with a potential temporal misplacement of observations. The two consecutive $24-\mathrm{h}$ periods with coincident observations are highlighted in black. (b) Records from Aguilar de Codés and AoizAgoitz during a potential spatial misplacement of observations. The black solid line highlights the coincident records on $1 \mathrm{Jul}$.

a given station is compared against all the 8-h periods of the rest of the stations. The imposition of variance higher than zero, both in the temporal and in the spatial assessments, is to avoid periods with constant measurements, which will be treated in subsequent checks. A typical coincident interval in the measurements of two stations is displayed in Fig. 3b. The wind speed time series from Aguilar de Codés and Aoitz-Agoitz are coincident during one day. Wind direction presents a similar behavior with coincidences in the same day as wind speed (not shown). The identical wind observations were finally removed from the time series of both stations.

\section{b. Limits consistency}

After correcting for manipulation errors, a limits consistency check to remove unrealistic observations is applied (Fig. 2). This check imposes high and low limits 
for the possible values of one variable and considers invalid the observations outside the range allowed. The threshold values could be based either on static or dynamic climatic extremes or on the response ranges of the given sensors (Meek and Hatfield 1994). In this QA, the limits are fixed depending on the anemometer characteristics. Hence, the low wind speed limit is fixed at $0.0 \mathrm{~m} \mathrm{~s}^{-1}$, and the high limit to $60.0 \mathrm{~m} \mathrm{~s}^{-1}$ for the RN and GN stations and to $50.0 \mathrm{~m} \mathrm{~s}^{-1}$ for the AEMET stations. For the case of wind direction, a low limit of $0^{\circ}$ and a high of $360^{\circ}$ are selected.

\section{c. Temporal consistency}

The next step of the QA is to ensure the temporal consistency of the time series (Fig. 2). Wind speed checks are divided into two groups: the first one looking for periods with abnormally low variations and the second for records with abnormally high variations. For the case of a wind direction time series, only temporal consistency checks that look for periods with abnormally low variations are applied. This is because the effects of turbulence are relevant in the time scales considered (10 and $30 \mathrm{~min}$ ) and can produce relatively fast and large changes, within which even a reversal in wind direction between two consecutive records could be argued to be valid.

\section{1) ABNORMALLY LOW VARIATIONS}

Abnormally low variations are those periods that present extremely long constant observations. In the case of wind speed, a difference is made between periods of constant wind speed equal or higher than $1.0 \mathrm{~m} \mathrm{~s}^{-1}$ and those of wind speeds lower than $1.0 \mathrm{~m} \mathrm{~s}^{-1}$. This allows for the separate treatment of repetitions associated with calm periods and those related to other phenomena. This differentiation was performed in a previous wind QC (DeGaetano 1997). The wind speed limit that separates calm and noncalm should be the cut-in wind speed of the anemometer because lower wind speed measurements result from averaging over one or more zero records. The selection of $1.0 \mathrm{~m} \mathrm{~s}^{-1}$ agrees with the cut-in wind speed of the GN and RN sensors (see section 2). The possibility of selecting a threshold of $0.3 \mathrm{~m} \mathrm{~s}^{-1}$ for AEMET stations was considered because this is the cut-in wind speed of its sensors. However, to maintain this theoretical cut-in wind speed of $0.3 \mathrm{~m} \mathrm{~s}^{-1}$, strict maintenance operations of the sensors would have been necessary to mitigate its deterioration by the effects of adverse meteorological conditions (Fiebrich et al. 2006). Because there are no metadata available to evaluate whether maintenance operations were adequate, and some preliminary inspections revealed that the sensor accuracy could indeed have deteriorated, the limit between calm and noncalm wind

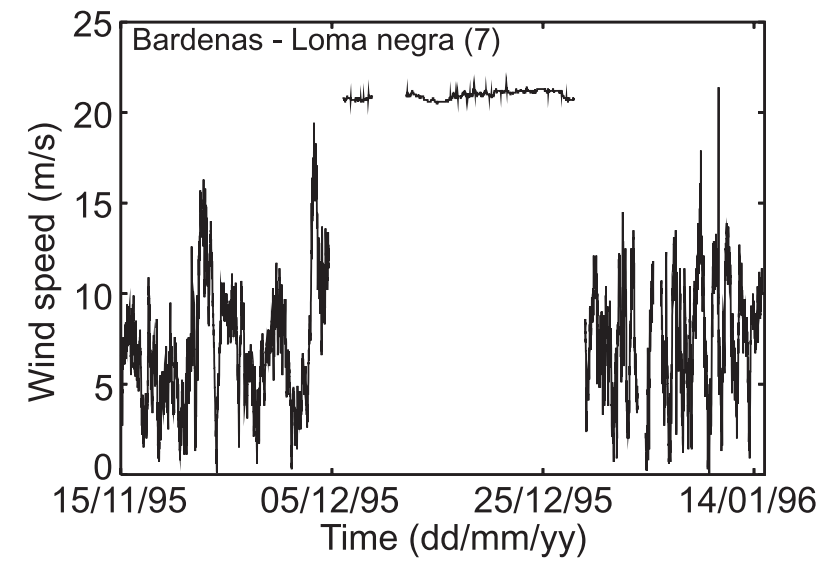

FIG. 4. Wind speed measurements from Bardenas-Loma negra showing a cluster of repetitions.

speeds for these stations was fixed, as in the rest of stations, to $1.0 \mathrm{~m} \mathrm{~s}^{-1}$.

Repetitions of wind speeds equal or higher than $1.0 \mathrm{~m} \mathrm{~s}^{-1}$ usually appear in clusters. These periods of dubious quality are manually analyzed and suppressed if considered appropriate. A typical case is displayed in Fig. 4. Repetitions of wind speed values of around $21 \mathrm{~m} \mathrm{~s}^{-1}$ over 20 days can be observed. Furthermore, periods exist with missing values before, between, and after the repetitions. The veracity of this group of measurements is highly questionable, and thus the whole period of repetitions was considered invalid.

If repetitions of wind speeds higher than $1.0 \mathrm{~m} \mathrm{~s}^{-1}$ do not appear in clusters (e.g., Fig. 4), the manual inspection becomes unavoidable. In this case, a reasonable estimation of the length of a repetition considered valid is established by analyzing, first, the number of repetitions as a function of its temporal duration, and then the number of stations providing one or more constant records of a given duration (Fig. 5). This second analysis was used by DeGaetano (1997) to assess abnormally low variations of wind direction observations. For the present dataset, both analyses show similar characteristics and either one could be used to estimate a reasonable maximum duration of a constant wind speed episode. For short durations, constant wind periods are reported by all stations with a high frequency of occurrence. As duration increases, an abrupt decrease in the frequency of constant wind periods appears and a drop in the number of stations experiencing it, demonstrating that the phenomenon is infrequent. Both procedures reach zero (absolute frequency or number of stations) at 11 constant wind measurements. Constant periods of longer duration are very infrequent in the group of stations, which suggests eleven 10-min intervals as a reasonable choice for the maximum number of constant records 


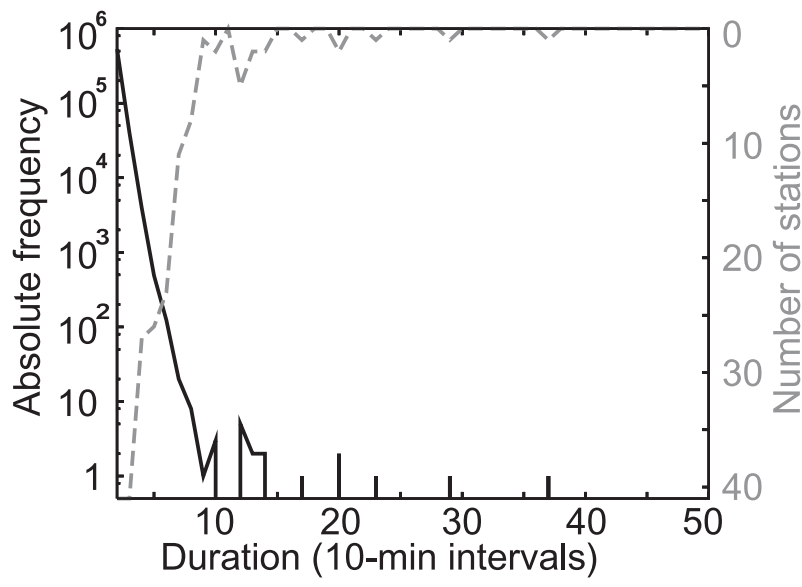

FIG. 5. Frequency of occurrence of periods with constant 10-min records vs their temporal duration (solid line), and the number of stations reporting one or more periods of constant wind speed records of a given duration (dashed line). Only wind speeds equal or higher than $1.0 \mathrm{~m} \mathrm{~s}^{-1}$ are used. Notice the reverse of the scale for the number of stations.

allowable. Hence, periods of constant wind speed equal to or higher than $1.0 \mathrm{~m} \mathrm{~s}^{-1}$ are considered invalid if their duration is equal to or longer than $1 \mathrm{~h}, 50 \mathrm{~min}$. The 30-min wind speed observations show repetitions of two records but very few of three, and thus there were no corrections for them.

Repetitions of wind speeds lower than $1.0 \mathrm{~m} \mathrm{~s}^{-1}$ are more frequent than repetitions of higher wind speeds because of the presence of calm periods and several questionable periods that tend to report the zero value. Some of these periods are inordinately long, even more than 20 days recording zero, which seems to be produced by a malfunctioning of the weather station. Other periods of constant zero wind speed measurements seem to have been caused by the freezing of the wind sensor, such as that displayed in Fig. 6 where the wind speed records show zero values for more than four consecutive days. During these days, the temperature was below $0^{\circ} \mathrm{C}$ and the relative humidity close to $100 \%$. In these atmospheric conditions, the excess of water vapor in the saturated air must change its phase into ice. These conditions plus a relatively weak wind could freeze the wind sensor, leading to zero wind speed values. The period in which the sensor could be frozen finishes when very high wind speeds are measured. The hypothesis of freezing sensors is confirmed by metadata that reveal the presence of ice in the anemometers at the highest locations.

To suppress questionable periods, such as those previously mentioned, a reasonable value for the maximum number of constant measurements associated with calm was estimated. This might be done with an analysis similar to that used for the isolated periods of constant

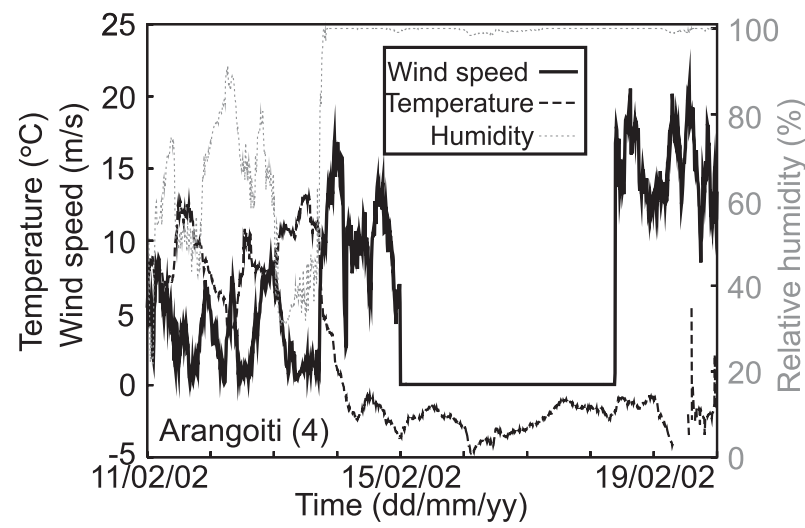

FIG. 6. A period with constant wind speed records of zero $\mathrm{m} \mathrm{s}^{-1}$ from station Arangoiti. The wind speed time series is represented by a solid line, whereas the time series for temperature and humidity is displayed with dashed and dotted lines, respectively.

wind speed greater than $1.0 \mathrm{~m} \mathrm{~s}^{-1}$ (Fig. 5). However, it could be argued that the duration of the constant durations associated with calm depends on the specific location of the station. Different sites present different wind speed distributions, which can affect the length of the calm periods. This is illustrated in Fig. 7a, which shows the number of repetitions associated with calm records as a function of their duration for each station. The different length and frequency of calm periods depend on the location. This different behavior can be better understood by comparing the number of repetitions associated with calm against a parameter representative of the wind characteristics of the particular location, such as the mean wind speed. Such a comparison is displayed in Fig. 7b. The number of constant periods associated with calm decreases with the mean wind speed of the location. Therefore, the reasonable maximum duration of a constant period associated with calm should be calculated for each individual time series. This is done by analyzing the frequency of constant periods as a function of its duration for each station independently (Fig. 7a), and selecting a suitable value to remove infrequent repetitions in a similar way as for isolated wind speeds exceeding $1.0 \mathrm{~m} \mathrm{~s}^{-1}$ (see the previous discussion concerning Fig. 5).

After screening for abnormally low variations in the wind speed time series, the same was done for wind direction (Fig. 2). Zero wind direction records are excluded from the analysis because they are associated with calm periods (see section 2) that were already assessed by the previous checks. Again, a reasonable number of admissible constant wind direction measurements are established by analyzing the frequency of 10 -min periods of constant wind direction as a function of their duration and the number of stations that present 

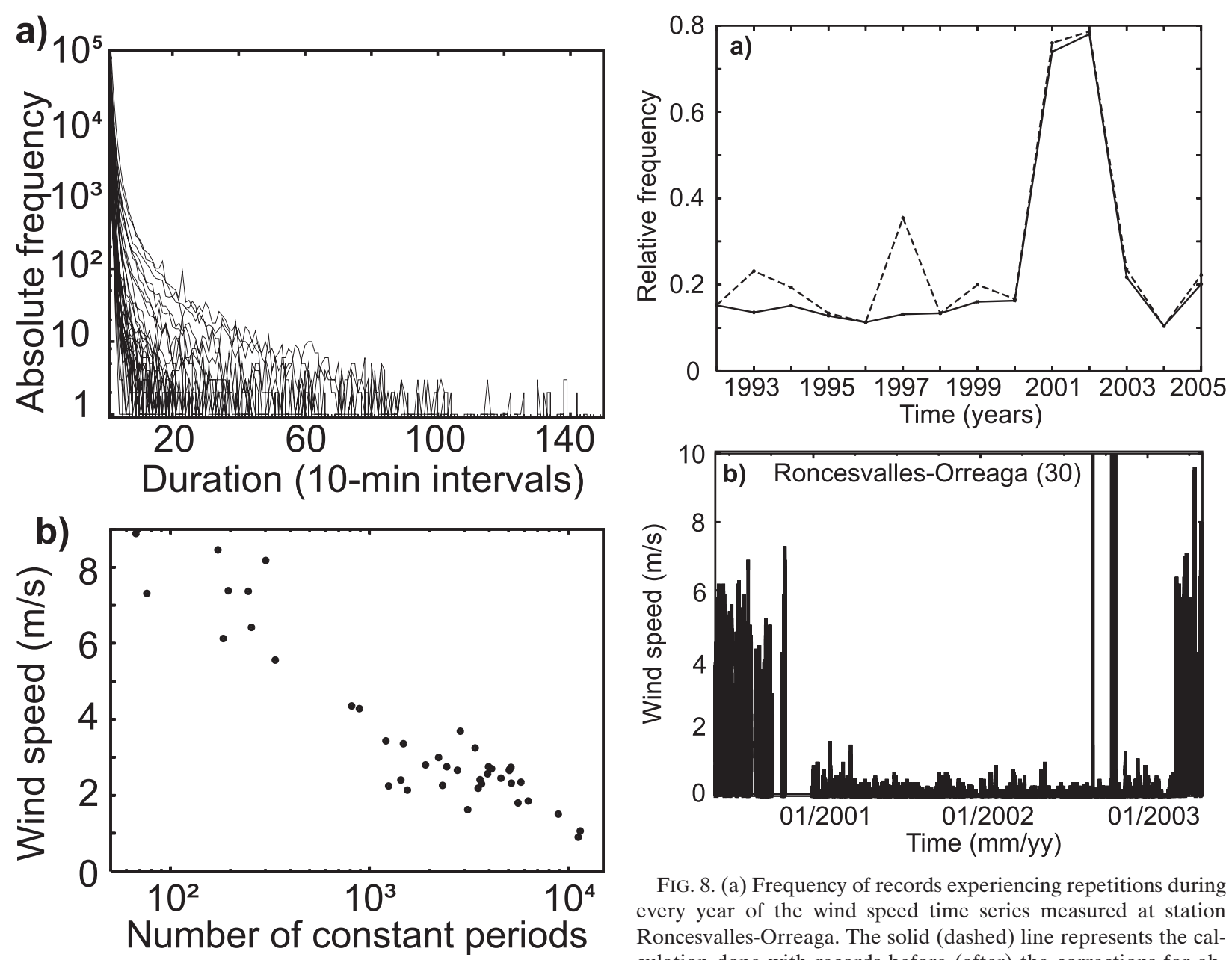

FIG. 8. (a) Frequency of records experiencing repetitions during every year of the wind speed time series measured at station Roncesvalles-Orreaga. The solid (dashed) line represents the calculation done with records before (after) the corrections for abnormally low variation periods. (b) A period of the wind speed time series.

wind speed (a) Absolute frequency of periods of constant 10 -min vs the number of constant wind speed periods. Each line in (a) or point in (b) represents an observational time series. Only periods of constant wind speeds lower than $1.0 \mathrm{~m} \mathrm{~s}^{-1}$ are considered.

one or more constant wind direction periods for the given durations. The analysis suggests 40 as a reasonable limit for the maximum number of constant measurements allowed (not shown). Hence, 10-min wind direction measurements repeated during $400 \mathrm{~min}$ or longer durations are considered invalid. For the 30-min wind direction measurements, this occurs at four repeated records, and repetitions equal to or longer than this limit $(2 \mathrm{~h})$ were also assumed invalid.

The completion of this stage of the QA represents a first step in the assessment of questionable periods associated with abnormally low variations from both the wind speed and direction time series (Fig. 2). The next step consists of a check that analyzes the frequency of constant measurements within each year before and after the corrections of the previous checks. The purpose of the

analysis is to inspect the year-to-year variability in the number of repetitions and inspect the cause of any abnormal behavior detected. The check was applied separately to each one of the wind speed and direction time series. None of the time series present an abrupt decrease in the frequency of constant measurements, which is indicative of an excessive suppression of measurements by the previous checks. In contrast, most of the stations show a reduction in the number of repetitions in years with an abnormally high frequency of repetitions. Figure 8a shows an illustrative example from the station of Roncesvalles-Orreaga. The corrections suppress a peak in 1997 and other secondary peaks in 1993 and 1999, keeping the frequency of repetitions approximately constant during the 1990s. However, during 2001 and 2002, around $80 \%$ of the records are associated with repetitions. An inspection of the wind speed time series shows abnormally low values in the questionable period (Fig. 8b). Note that wind speed records before and after this period 
present different degrees of variability. Because of the questionable veracity of the records, it was decided to assume as invalid the period running from the beginning of 2001 to the first months of 2003. Similar cases were detected by this test in other stations. All the questionable periods identified were analyzed manually to suppress unrealistic observations, such as those mentioned above (Fig. 8b).

\section{2) ABNormally high VARIATIONS}

Abnormally high temporal variations of wind speed records are first assessed with a step check (Fig. 2), which calculates the difference between two consecutive records and, if higher than a threshold value, the second record is considered invalid. The choice of the threshold value is a controversial decision that depends on the location and the temporal resolution of the data. Meek and Hatfield (1994) recommended critical values of 7.5 and $10.0 \mathrm{~m} \mathrm{~s}^{-1}$ for hourly and daily data, respectively, whereas Bailey and McDonald (1997) suggested a value of $5.0 \mathrm{~m} \mathrm{~s}^{-1}$ for hourly data. Other authors (e.g., Vejen et al. 2002) proposed a dynamic critical value, which changed as a function of the month of the year; in their case, values of $6.0,7.0$, or $8.0 \mathrm{~m} \mathrm{~s}^{-1}$ for hourly data in Denmark. Thus, the selection of this threshold value depends on the particular wind characteristics of the region, among other factors. In the present QA, the threshold value is selected by analyzing the histogram of the absolute differences for every wind speed time series. A representative example is displayed in Fig. 9a. The frequency of the differences gradually decreases and is null at $10.0 \mathrm{~m} \mathrm{~s}^{-1}$. However, there appears to be one case with a difference of $28 \mathrm{~m} \mathrm{~s}^{-1}$ and another with $29 \mathrm{~m} \mathrm{~s}^{-1}$, which causes a large break in the histogram. The great length of the break in the histogram and the low frequency of occurrence make $10 \mathrm{~m} \mathrm{~s}^{-1}$ a good candidate for the threshold values for this case. Other stations do not present a break in the histogram, the null frequencies being reached at slightly different wind speeds. For instance, the stations from RN reach the null frequencies around $6 \mathrm{~m} \mathrm{~s}^{-1}$ for both the 10- and 30-min wind speed observational time series. These considerations let us take $10 \mathrm{~m} \mathrm{~s}^{-1}$ as a reasonable choice for the threshold value used in the step check.

The step above is unsuitable for assessing those records that are followed or preceded by a missing value because the difference obviously cannot be calculated. In fact, some abnormally high wind speed records are surrounded by missing values that are not detected by the step check and should be labeled as invalid (Fig. 9b). To assess this type of record, an analysis of the daily maximum 10-min wind speed against the daily mean is
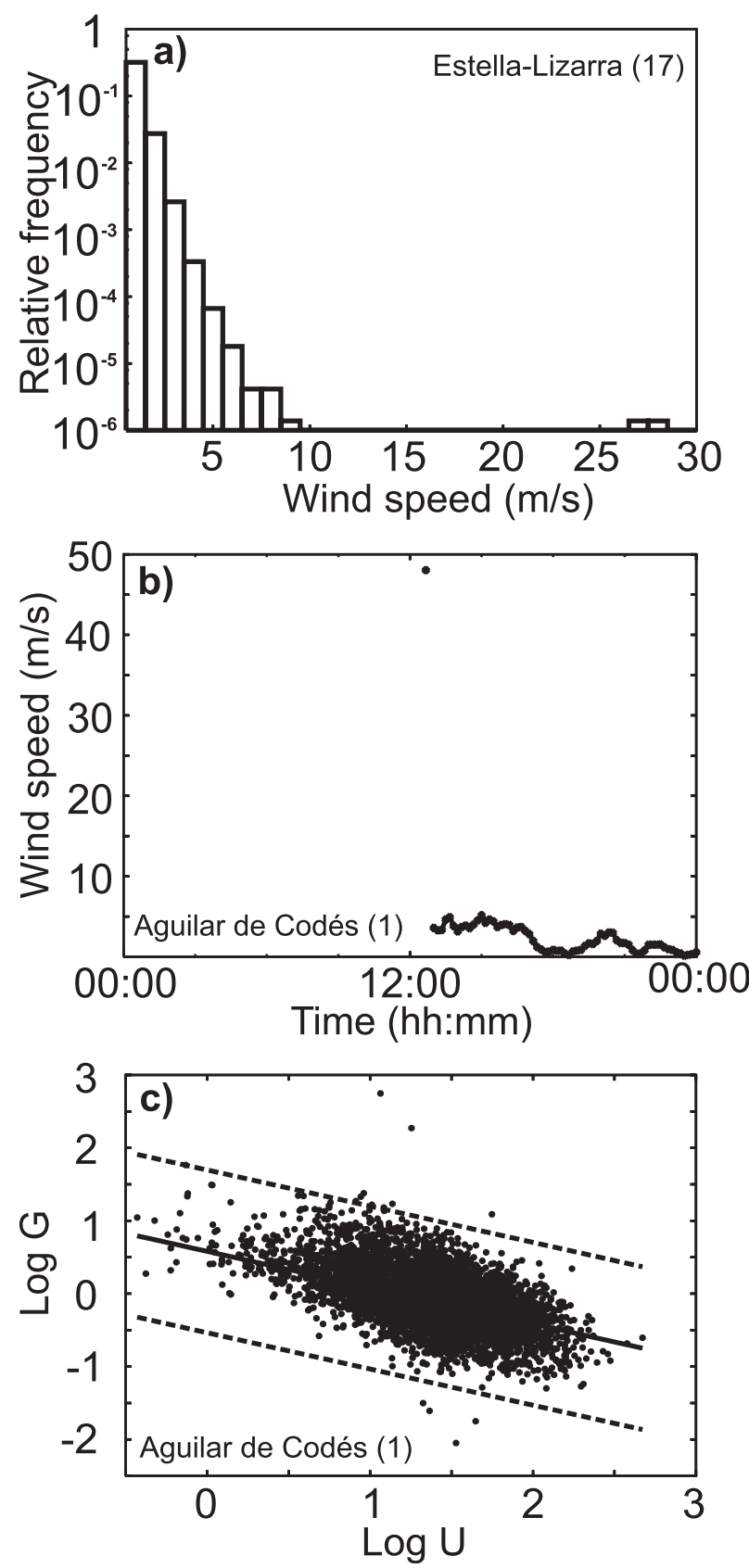

FIG. 9. (a) Absolute value of the differences between consecutive wind speed records of Estella-Lizarra. (b) Wind speed records measured at Aguilar de Codés showing abnormally high variations. (c) Logarithm of the gust factor [see Eq. (1)] vs the logarithm of the daily mean also for station Aguilar de Codeés. The solid line in (c) represents the linear regression fit and the dashed lines the $95 \%$ confidence intervals.

performed (Fig. 2). This is done in a similar way to that used by Graybeal (2006) to assess daily peak gust records. Graybeal used the gust factor defined as

$$
G=u_{g} U^{-1}-1
$$


where $u_{g}$ is the peak gust, and $U$ is the daily wind speed mean. The normalization provides a certain degree of robustness to the exposure characteristic of instrument siting (Paulsen and Schoeder 2005). Graybeal then used the well-known linear relationship between $\log G$ and $\log U$ (Weggel 1999; Jungo et al. 2002) to fit a linear regression and to establish prediction intervals. Because outliers are present in the observations, the parameters of the linear regression were calculated with a resistant technique like the least-trimmed squares regression (Venables and Ripley 1999). Furthermore, resistant estimators, such as the biweight mean and standard deviation (Lanzante 1996), were used to calculate the variance of the predictions to establish prediction intervals (see Graybeal 2006 for more details). In this study, $u_{g}$ is replaced by daily maximum 10 -min wind speed to calculate $G$ [Eq. (1)]. Only those days with no missing values are used to more accurately calculate the linear regression parameters, and the $95 \%$ confidence prediction intervals, after checking that residuals are normally distributed. Once the prediction intervals are calculated, all days with a minimum of ten 10-min wind speed records available are used to calculate the $\log G$ and $\log U$. All days outside the prediction threshold are reported and manually analyzed to assess the questionable records. As an example, the linear fit and the prediction intervals for observations in the station of Aguilar de Codés are displayed in Fig. 9c. After manually analyzing the measurements for the days outside the prediction intervals, the anomalously high value, which could not be detected by the step check because of the presence of missing values (Fig. 9b), was identified.

\section{QA methodologies: Systematic errors}

As a final step in the evaluation of the potential errors of the dataset, the systematic errors or biases of the wind speed and wind direction time series are analyzed (Fig. 2). These errors should be detected and adjusted with a homogenization procedure (Peterson et al. 1998a). In the past, this type of procedure has mostly been applied to annually and monthly averaged records (e.g., Alexanderson 1986; Karl and Williams 1987; GonzálezRouco et al. 2001). The use of the homogenization methodologies to adjust records of higher temporal resolution is a delicate task because the higher variability of the records introduces fresh problems (Aguilar et al. 2003). Recently, effort has been directed at developing suitable methodologies to homogenize daily temperature and precipitation time series (e.g., Vincent et al. 2002; Wijngaard et al. 2003; Della-Marta 2006). Hence, application of the available homogenization procedures to the present dataset of 10 and $30 \mathrm{~min}$ is, at best, delicate. As a consequence, no homogenization procedure was used to adjust the potential biases of the present dataset. Instead, two checks directed at analyzing the long-term behavior of the time series were applied to the data to deal with the most important biases. Although application of these checks contributes to homogenizing the time series, the process cannot be called in a strict sense homogenization, because that would require the application of more sophisticated homogenization procedures.

Systematic errors may introduce biases in the mean or the variance of the time series. Hence, one of the checks applied deals with the long-term behavior of the mean and the other with the variance. The checks consist of analyzing a moving average and a moving variance with a 30-day window length applied to the wind speed and direction time series. Actually, both moving time series are analyzed together, and they are considered a single check (Fig. 2). For the case of positively defined variables with a low limit in the records, a greater mean involves higher variability (wider distribution) and so both statistics tend to show a direct relationship (Xoplaki et al. 2004; Jiménez et al. 2008). Thus, it can be argued that inhomogeneities in the mean will also introduce inhomogeneities into the variance for this kind of variable. The wind speed is a clear example of a positively defined variable with a low limit (zero). To illustrate the above theoretical considerations, the moving variance as well as the moving average of the wind speed time series observed at Aoiz-Agoitz are displayed in Fig. 10a. An excessively high increase in wind speed variations at the beginning of 1997 can be recognized. The moving average shows a similar behavior. An inspection of the records corresponding to the high values reveals a change in both the mean and variance of the time series (Fig. 10b). After this anomalous period, a missing period appears and then the wind speed records recover their regular range of variation. Unfortunately, no metadata are available for this period to look for possible explanations. However, the change in variance and the presence of the missing period after the abnormally high measurements considerably reduce the reliability of these records, and so the period was considered invalid.

The moving average and the moving variance of the wind direction time series were calculated using directional statistics (Mardia and Jupp 1999). A common problem identified by these checks can be found in the records of the station at Isaba. The moving variance, normalized by the variance of the complete time series, varies around 1.0, but there are abnormally low values at the end of the time series (Fig. 11a). The analysis of the questionable period shows wind direction measurements with an anomalous range of variation (Fig. 11b). More than 1 year of records show that wind direction is restricted to a smaller than 

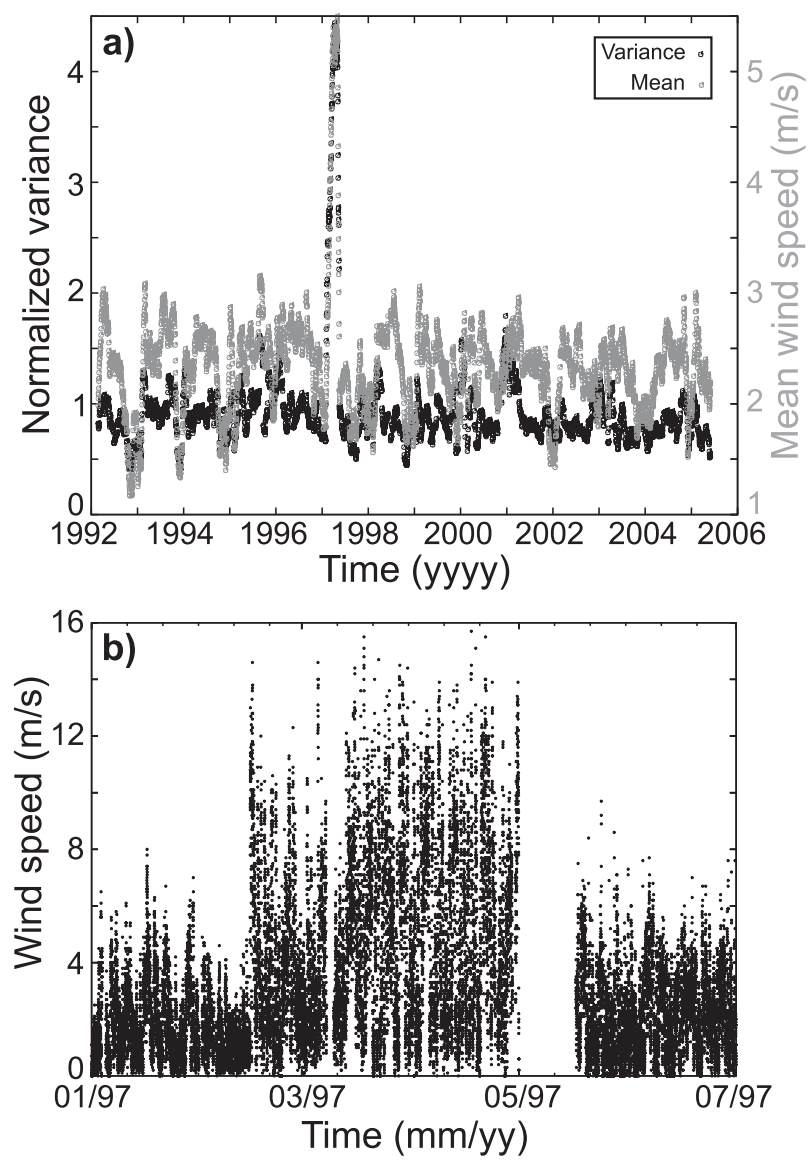

FIG. 10. (a) A 30-day moving variance (black dots) and 30-day moving average (gray dots) of the wind speed records measured at station Aoitz-Agoitz. The moving variance is normalized by the variance of the complete time series. (b) A period with questionable records from the wind speed time series.

natural range of values (i.e., between $0^{\circ}$ and $360^{\circ}$ ), probably due to faulty wind vane bearings. The complete period of anomalous variability was removed from the time series. Similar changes in variance were identified and suppressed in other stations.

Other moving averages show steps in the time series that can be associated with failures in the wind vane fixation. The origin for the wind direction records is from the north direction; however, there are periods wherein this zero reference has changed for some unknown reason, and this introduces a systematic error in the records. One of these cases can be observed in the moving average from the Pamplona-Larrabide station shown in Fig. 12. Three different steps can be recognized in the moving average defining periods with different means (Fig. 12a). Inspection of the records for each period did not reveal anything suspicious. However, metadata show a wrong setting of the reference (north) on 18 September 2001, suggesting that a correction of
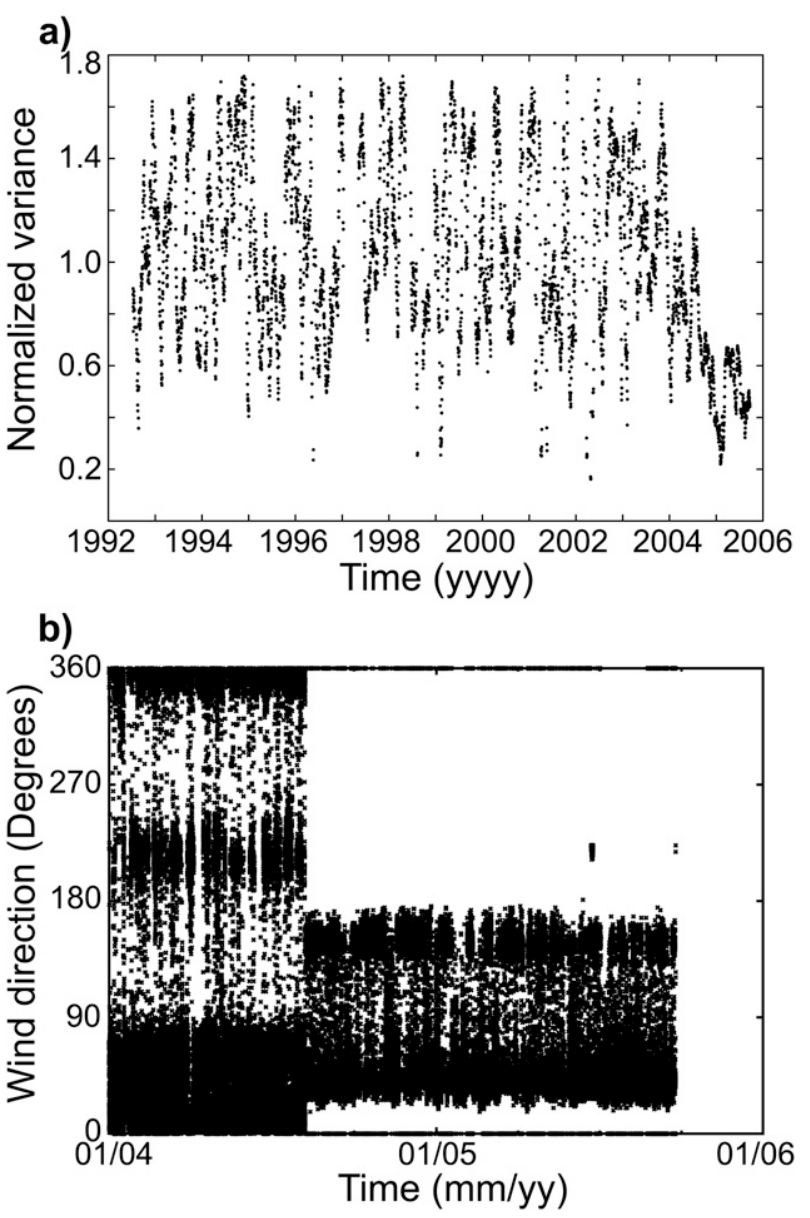

FIG. 11. (a) Normalized 30-day running variance of the wind direction records measured at Isaba station and (b) a selected period of the wind direction time series.

$60^{\circ}$ should be applied to the previous measurements. This date coincides with the abrupt change observed in the moving average time series, which defines the end of the second period shown in Fig. 12a. The wind roses for the previously mentioned periods present similar shapes, but they are rotated with respect to each other (Fig. 12b). The wind rose of the second period needs to be rotated $57^{\circ}$ to reach good concordance with the one corresponding to the third period (Fig. 12d). This is in good agreement with metadata suggestions and therefore $57^{\circ}$ are subtracted from the records of the second period. Furthermore, knowing that the wind vane was fixed on a certain date defines a reference for good calibrating of the measurements, and $10^{\circ}$ is the correction applied to the first period to be in concordance with the rest (Fig. 12d). After these corrections, the moving average of wind direction records does not present abrupt changes, and so the time series presents similar mean wind direction (Fig. 12c). All the questionable periods 


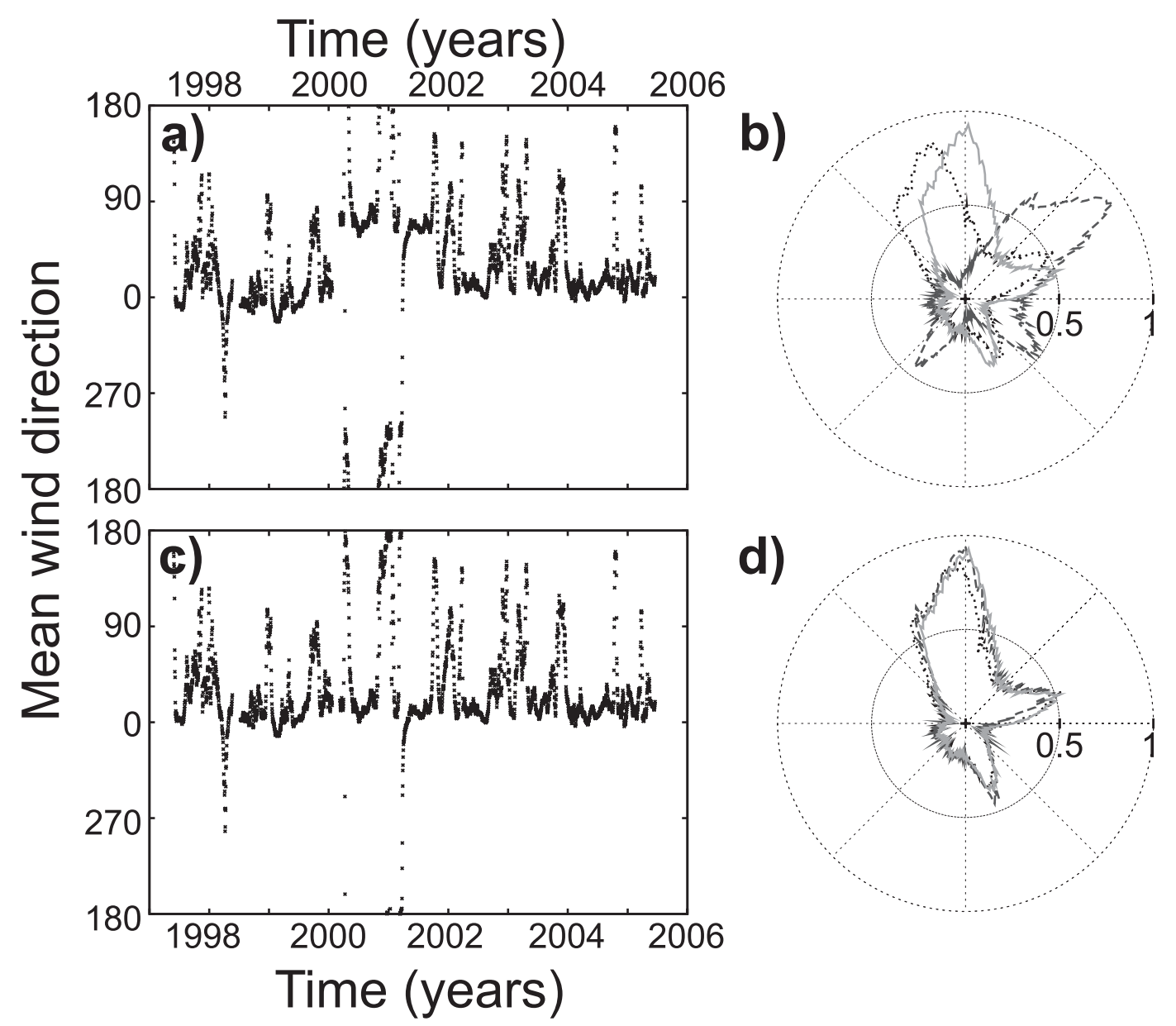

FIG. 12. Normalized 30-day moving variance of the wind direction records reported at station Pamplona-Larrabide (a) before and (c) after the correction of its anomalous variability. The wind rose (b) before and (d) after corrections for three different periods: 1 Jan 1997-1 Feb 2000 (dotted line), 1 Feb 2000-18 Sep 2001 (dashed line), and 18 Sep 2001-27 Jun 2005 (solid line) are also shown.

showing this kind of problem were manually analyzed to compensate for the systematic errors of the time series.

\section{QA results: Rough errors}

This section presents the spatiotemporal distribution of records invalidated by each check dealing with rough errors in the QA (Fig. 2). The number of measurements invalidated by each check is summarized in Table 2 .

\section{a. Manipulation errors}

A total of 33037 wind speed records $(0.171 \%)$ and 32645 wind direction records $(0.169 \%)$ were removed from the original time series in this step. Errors associated with a temporal misplacement of observations are more frequent than those associated with an incorrect spatial assignment (Table 2). The spatial and temporal distributions of the records that are assumed invalid by each one of the two checks are shown in Figs. 13a and 13b, respectively.

Stations from the three institutions, GN, AEMET, and RN, present coincident observations in their own time series, which we here attribute to a wrong temporal assignment of observations (Fig. 13a). The number of cases that are assumed invalid reached a maximum in 1999 (Fig. 13b). During this year, the wind speed and direction records for 1 November and 1 December coincided in a total of nine stations, all from GN. The magnitude of the wind speed measurements shows abrupt breaks before and after the coincident records for the time series that includes 1 November. In contrast, the time series that includes the records associated with 1 December do not show abrupt changes at these points. This different behavior seems to suggest a wrong assignment of the observations from 1 December 1999 to 
TABLE 2. Number of records invalidated by each step of the QA (Fig. 2). The percentage of invalidated records with respect to the original number of records is shown in brackets $(\%)$.

\begin{tabular}{lrr}
\hline \hline \multicolumn{1}{c}{ Check } & Wind speed & Wind direction \\
\hline Manipulation error (temporal) & $23128(0.120)$ & $22810(0.118)$ \\
Manipulation error (spatial) & $9909(0.051)$ & $9835(0.051)$ \\
Limits consistency check & $518(0.003)$ & $555(0.003)$ \\
Abnormally low variations & & - \\
Wind speeds $>1 \mathrm{~m} \mathrm{~s}^{-1}$ (cluster repetitions) & $51592(0.267)$ & - \\
Wind speeds $>1 \mathrm{~m} \mathrm{~s}^{-1}$ (single repetitions) & $375(0.002)$ & - \\
Wind speeds $<1 \mathrm{~m} \mathrm{~s}^{-1}$ (single repetitions) & $119112(0.616)$ & - \\
Wind direction (single repetitions) & $133587(0.691)$ & $796(0.501)$ \\
Repetitions in different years & $305(0.002)$ & $926(0.479)$ \\
Abnormally high variations & $719(0.004)$ & - \\
Step check & $10450(0.054)$ & - \\
Daily mean vs daily max & $349695(1.809)$ & $497945(2.576)$ \\
Biases & & $7205(3.728)$ \\
Total & & \\
\hline
\end{tabular}

those from 1 November 1999, which would contribute to the high number of cases detected during this year (Fig. 13b).

Most of the records assumed as invalid by the spatial check are coincident observations in stations managed by GN (Fig. 13a). The only exception is one case between two stations managed by AEMET. The total number of records assumed as invalid by the two checks shows a tendency to decrease over the years (gray line in Fig. 13b).

\section{b. Limits consistency}

There were no negative wind speed or wind direction records in the observational time series, but there were 518 wind speed measurements $(0.003 \%)$ higher than the maximum value measurable by the anemometers and 555 wind direction records $(0.003 \%)$ higher than $360^{\circ}$ (Table 2). The spatial and temporal distributions of the records removed after the application of the limits consistency check are shown in Figs. 13c and 13d, respectively.

The highest number of wind speed records assumed as invalid came from station Arangoiti, which presented 429 consecutive records of $444.4 \mathrm{~m} \mathrm{~s}^{-1}$ (Fig. 13c). The rest of the invalidated wind speed records are isolated values in the time series of stations managed by AEMET. For the wind direction, the suppressed records appear close to each other, defining an anomalous period. Only three periods were identified, the wind direction records associated with the previous records of $444.4 \mathrm{~m} \mathrm{~s}^{-1}$, which show values of $444.4^{\circ}$, and two periods registered at Aralar and Arangoiti. The invalidated records from both wind speed and wind direction time series are concentrated into the years 1999, 2000, and 2001, pointing to the inhomogeneous occurrence of this kind of error in the dataset (Fig. 13d).

\section{c. Temporal consistency}

The next two sections summarize the results obtained for the wind speed and the wind direction records.

\section{1) WIND SPEED}

A total of 304666 wind speed records (1.576\%) were invalidated by the group of checks dealing with abnormally low variations (Fig. 2). The spatial and temporal distributions of the measurements that are assumed invalid by each test are displayed in Fig. 14.

The suppression of clusters of repetitions of wind speeds higher than $1.0 \mathrm{~m} \mathrm{~s}^{-1}$ removes 51592 records $(0.267 \%)$ from the original dataset (Table 2$)$. All clusters of repetitions are similar to the one displayed in Fig. 4, and all the stations affected belong to GN (Fig. 14a). The single repetitions of wind speed higher than $1.0 \mathrm{~m} \mathrm{~s}^{-1}$ assumed as invalid are less frequent and only 375 records were removed $(0.002 \%)$. The records invalidated by this and the previous check are concentrated in the 1993-97 period (Fig. 14b), suggesting that the causes that originated these questionable records were repaired.

A total of $119112(0.616 \%)$ records were suppressed in the case of repetitions of wind speeds lower than $1.0 \mathrm{~m} \mathrm{~s}^{-1}$, a high percentage of which were associated with inordinately long periods with constant zero records. The stations managed by AEMET and the stations managed by GN located on mountaintops $(3,4,16$, 20, 35, and 37; see Fig. 1) show the highest number of suppressed records (Fig. 14c). As a result, the stations managed by GN and AEMET made the largest contribution to the total number of records invalidated by the check that analyzes the number of repetitions in different years (Fig. 14d). Note that the nine stations managed by AEMET present the same order of magnitude in the number of invalidated records as GN, which manages 

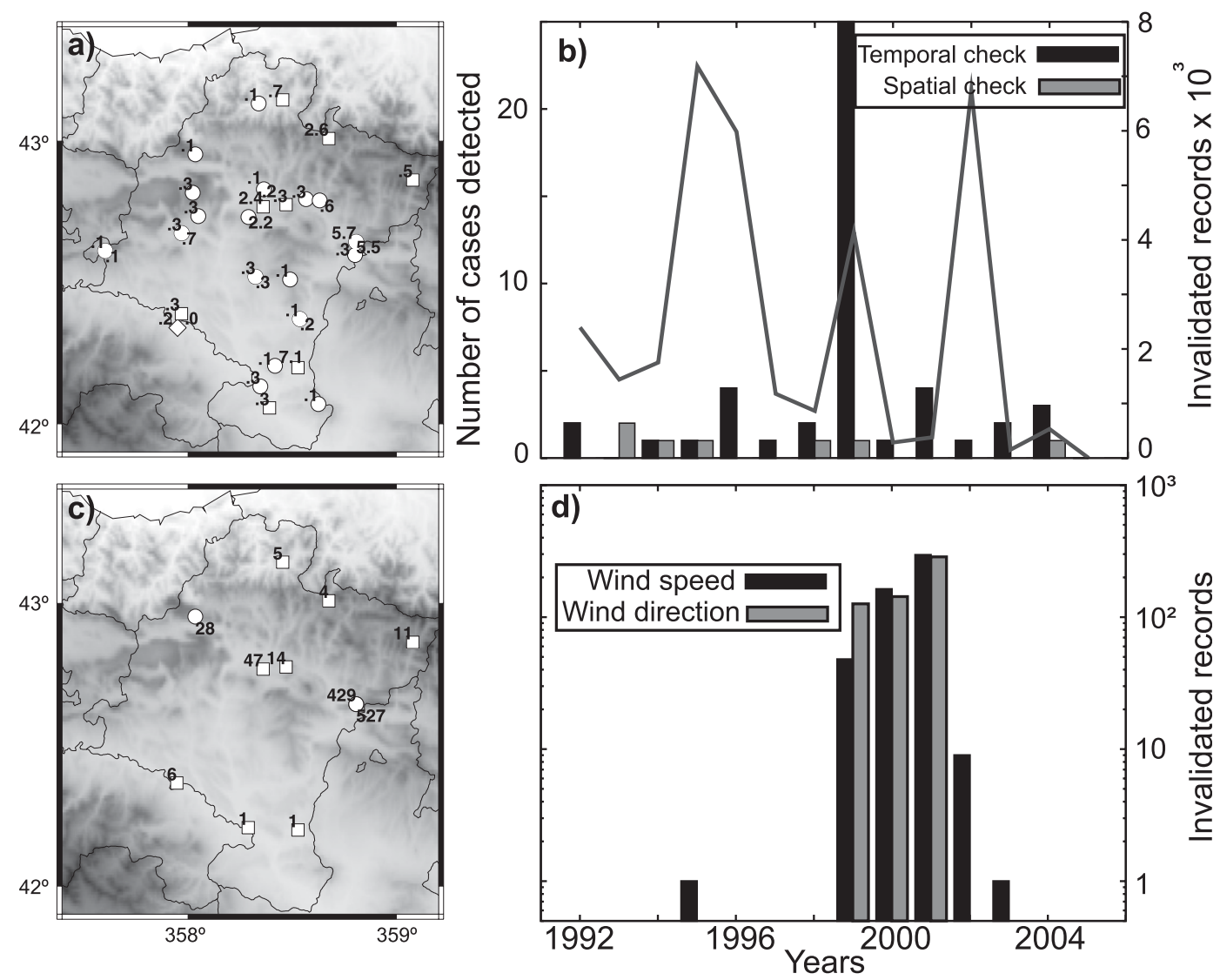

FIG. 13. (a) Spatial and (b) temporal distributions of the records invalidated by the checks associated with manipulation errors (Fig. 2). Circles, squares, and diamonds represent stations managed by GN, AEMET, or RN, respectively. The numbers to the left (right) of the symbols denote the thousands of records invalidated by the temporal (spatial) check. The black (gray) boxes in (b) represent the number of periods with coincident records assumed as invalid by the temporal (spatial) check, whereas the gray line represents the thousands of records invalidated by both checks. The (c) spatial and (d) temporal distributions of the records invalidated by the limits consistency check are also shown. The numbers to the left (right) of the symbols in (c) denote the number of wind speed (direction) records invalidated by the limits consistency check. The black (gray) boxes in (d) represent the number wind speed (wind direction) records assumed as invalid in each year.

25 stations. The seven stations managed by RN showed this kind of problem less frequently.

The check that evaluates the frequency of repetitions in different years invalidates a high percentage of measurements $(0.691 \%)$ from the wind speed time series (Table 2) because of the presence of long questionable periods such as those displayed in Fig. 8b. The stations that showed the largest corrections are again some stations managed by AEMET and mountaintop stations managed by GN (Fig. 14e). The distribution of the anomalous periods detected by this check is more or less homogeneous throughout the period of record (Fig. 14f).

The step check invalidates 305 wind speed records $(0.002 \%)$ and the analysis of the daily maximum wind speed versus the daily mean invalidates 719 (0.004\%). The spatial and temporal distributions of the measurements invalidated by these checks dealing with the abnormally high variations are displayed in Figs. 15a and $15 \mathrm{~b}$, respectively.

Again, it can be appreciated that certain stations from AEMET and the mountaintop stations from GN accumulate the largest number of invalidated records (Fig. 15a). The number of measurements removed shows a homogeneous distribution throughout the period of record for both checks (Fig. 15b).

\section{2) WIND DIRECTION}

A total of 189490 wind direction records $(0.980 \%)$ were assumed invalid by the checks dealing with the temporal consistency (Table 2). The spatial and temporal distributions of the measurements assumed invalid by each test are displayed in Figs. $15 \mathrm{c}$ and $15 \mathrm{~d}$, respectively. 

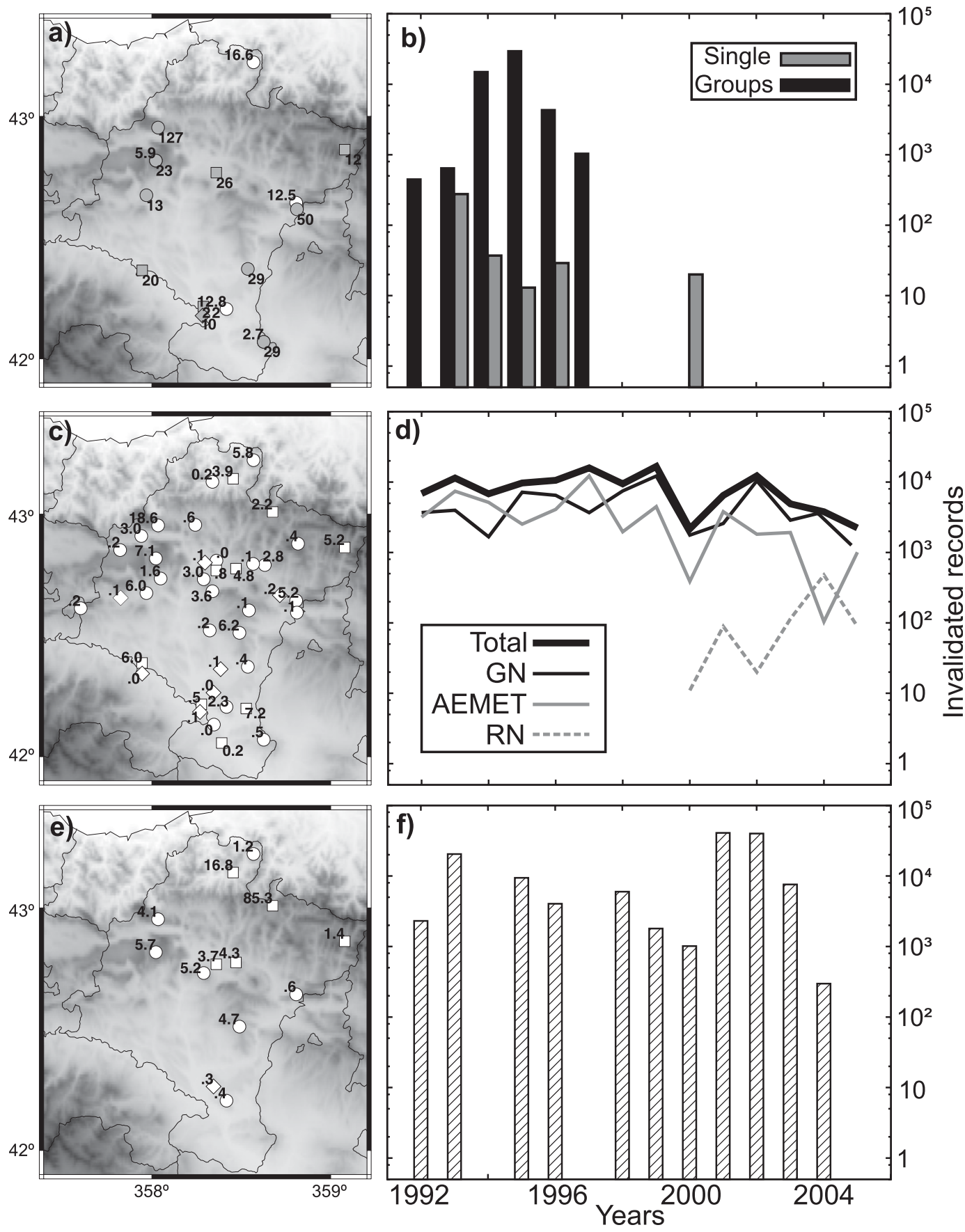

FIG. 14. (left) Spatial and (right) temporal distributions of wind speed records invalidated by the checks associated with abnormally low variations (Fig. 2). Circles, squares, and diamonds represent stations managed by GN, AEMET, or RN, respectively. (a) The numbers to the left (right) of the symbols denote the thousands (number) of wind speed records higher than $1.0 \mathrm{~m} \mathrm{~s}^{-1}$ invalidated by the check that deals with clusters of (single) repetitions. (b) The black (gray) boxes represent the number of records assumed as invalid in each year by the check dealing with clusters of (single) repetitions. (c) The thousands of records invalidated by the check dealing with repetitions of wind speed records lower than $1.0 \mathrm{~m} \mathrm{~s}^{-1}$ are shown, and (d) the temporal distribution of these invalidated records. (e) The number of records invalidated after analyzing the number of repetitions in different years and (f) the temporal distribution of these suppressions. 

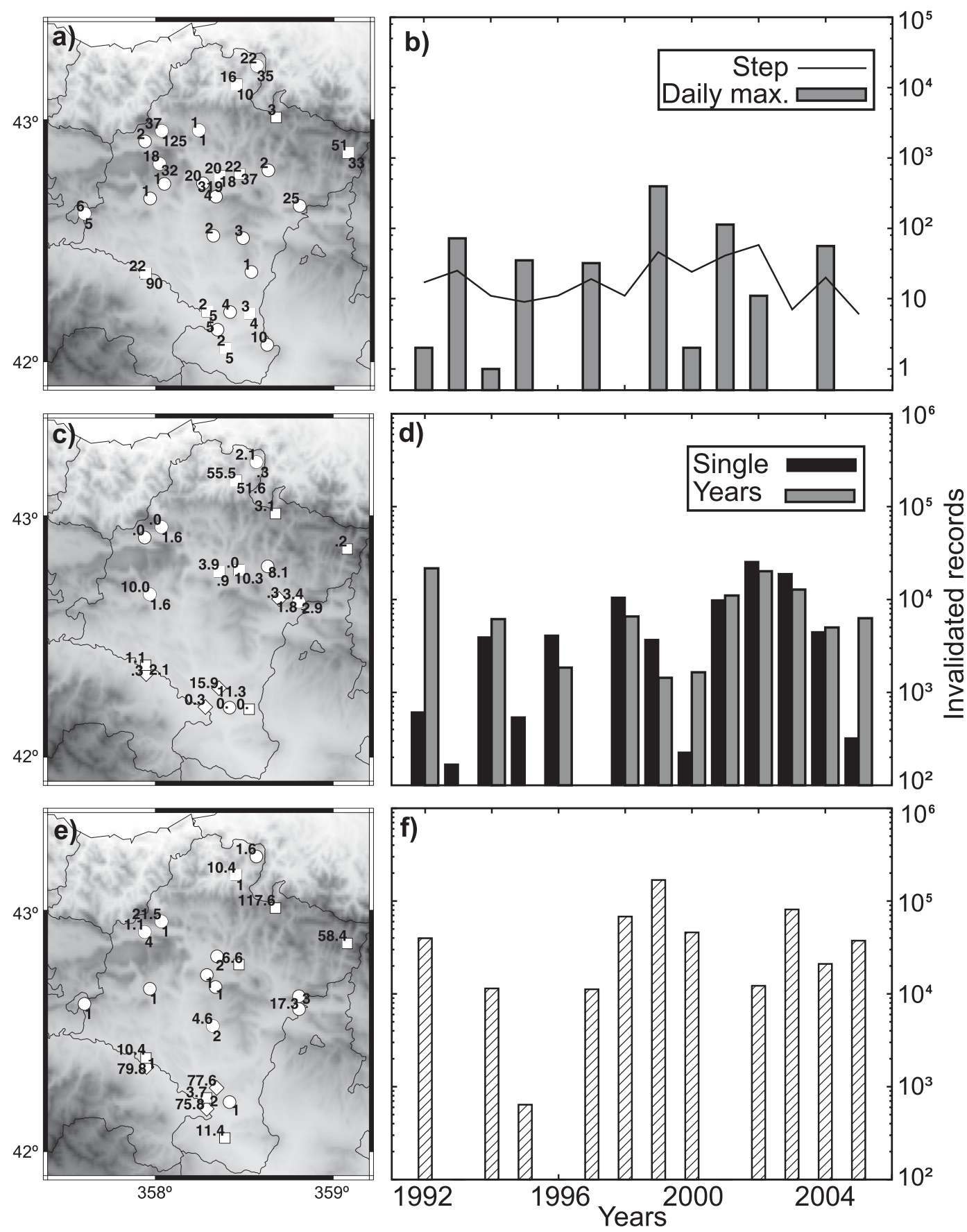

FIG. 15. (a) Spatial and (b) temporal distributions of wind speed records invalidated by the checks that deal with the abnormally high variations (Fig. 2). Circles, squares, and diamonds represent stations managed by GN, AEMET, or RN, respectively. The numbers to the left (right) of the symbols in (a) denote the number of records invalidated by the step (daily mean vs daily max) check. The gray boxes (solid line) in (b) represent the number of records invalidated by the step (daily mean vs daily max) check. The (c) spatial and (d) temporal distributions of records invalidated by the checks associated with abnormally low variations of the wind direction time series (Fig. 2) are also shown. The numbers to the left (right) of the symbols in (c) denote the thousands of records invalidated by the check that deals with single repetitions (repetitions in different years), whereas the black (gray) boxes in (d) represent the temporal distribution of these suppressions. The (e) spatial and (f) temporal distributions of records invalidated by the checks associated with biases in the wind direction time series. The numbers to the left of the symbols in (e) denote the thousands of records invalidated, whereas the number to the right indicates the number of periods rotated to correct for wrong wind vane fixations. 
The check that suppresses repetitions considers a total of $96796(0.501 \%)$ wind direction records as invalid (Table 2). Stations managed by the three institutions, GN, AEMET, and RN, were affected by these corrections (Fig. 15c). The check analyzing the frequency of constant records in every year suppressed $92624(0.479 \%)$ additional records (Table 2). The records invalidated by these checks seem to be more frequent in recent years (Fig. 15d), probably due to the greater number of stations operative at the end of the observational period (Table 1). Most invalidated observations are constant or nearly constant measurements over a long period. For instance, the station at Bardenas-Barranco salado showed repetitions around $360^{\circ}$ for more than 1 year following the change in temporal resolution of its records (from 10 to $30 \mathrm{~min}$ ), suggesting a failure in the adjustments performed. The first check for isolated repetitions partially suppressed the erroneous records, $15.9 \times 10^{3}$ (Fig. 15c). The rest of the records, $11.3 \times 10^{3}$, were invalidated by the check that analyzes the frequency of repetitions in different years. A similar period was reported at Lekaroz that also shows a large number of invalidated records by these checks (Fig. 15c).

\section{QA results: Systematic errors}

Inspection of the 30-day moving means (variances) of the wind speed time series reveals time series that oscillate around their mean (variance) values without any unusual jumps. Several abnormally high peaks exist but show spatial consistency. The only case finally removed was the questionable period measured at Aoiz-Agoitz and displayed in Fig. 10b, a suppression of 10450 $(0.054 \%)$ wind speed records.

The screening for biases in the wind direction time series identified periods with abnormal ranges of variation (e.g., Fig. 11) and other periods associated with a wrong setting of the wind vane (e.g., Fig. 12). The errors associated with an anomalous range of variations usually present a long duration, which means that, after checking all questionable periods, a high percentage of records $(2.576 \%)$ are invalidated (Table 2 ). Problems with the setting of the wind vane affect a total of 13 stations. The spatial and temporal distributions of these corrections are shown in Figs. 15e and 15f, respectively.

Stations from all three institutions register anomalous periods of variation that affect a large number of records (Fig. 15e). The temporal distribution of the invalidated records reveals a more or less persistent problem in this respect throughout the period of record (Fig. 15f). The problems with the fixation of the wind vane are corrected in a similar way as in the station Pamplona-Larrabide, when metadata were available (Fig. 12). Otherwise, measurements corresponding to different periods of variability are rotated to be in concordance with the last period. This ensures that future extensions of the wind dataset will present similar wind direction variability. The only exception was station Cadreita-INM, for which no metadata were available and the different periods were rotated to be in concordance with the wind rose from the nearby Cadreita-Riegos station (Fig. 1), which does not present anomalous wind direction periods.

\section{Impact}

This section describes the impact that the QA introduced in the statistics of the observational time series. The percentage of records removed from each one of the original time series are displayed in Fig. 16. The percentage of missing values introduced in the wind speed time series is lower than $5 \%$, except for the station at Roncesvalles-Orreaga, where the percentage exceeds $10 \%$ (Fig. 16a). The large number of invalidated records at this site is a result of suppressing the long questionable period displayed in Fig. $8 \mathrm{~b}$ by the check dealing with the frequency of repetitions over the years. The missing values introduced in the time series of the wind direction are also, in general, lower than 5\% (Fig. 16b). However, a total of six stations show higher percentages of missing values, which, in five cases, exceed $10 \%$ (Fig. 16b). These large percentages are associated with the checks dealing with the repetitions in different years, as well as bias correction processes.

The impacts that the suppressions produced on the mean of the time series are displayed in Figs. 16c and 16d for the wind speed and wind direction, respectively. Changes in the mean wind speed showed a maximum value of $0.3 \mathrm{~m} \mathrm{~s}^{-1}$ at Roncesvalles-Orreaga. The wind direction time series showed larger impacts, with changes in the mean direction in excess of $30^{\circ}$. The standard deviation of the wind speed time series decreased in all stations (Fig. 16e) due to the invalidation of outliers and abnormally long periods recording zero wind records. Changes of up to $10 \%$ can be noticed at several stations. The standard deviation of the wind direction time series shows moderate changes, the largest being at BardenasBarranco Salado (Fig. 16f) due to the suppression of the long period with repetitions around $360^{\circ}$ already mentioned.

For the case of the wind speed time series, it is interesting to analyze the impacts that the corrections produced in higher-order moments, such as the skewness and the kurtosis (Fig. 17). The high values that the original time series showed at some locations (Figs. 17a and 17c) are reduced after the corrections (Figs. $17 \mathrm{~b}$ and $17 \mathrm{~d}$ ). The skewness is positive at all locations, revealing that the tail 

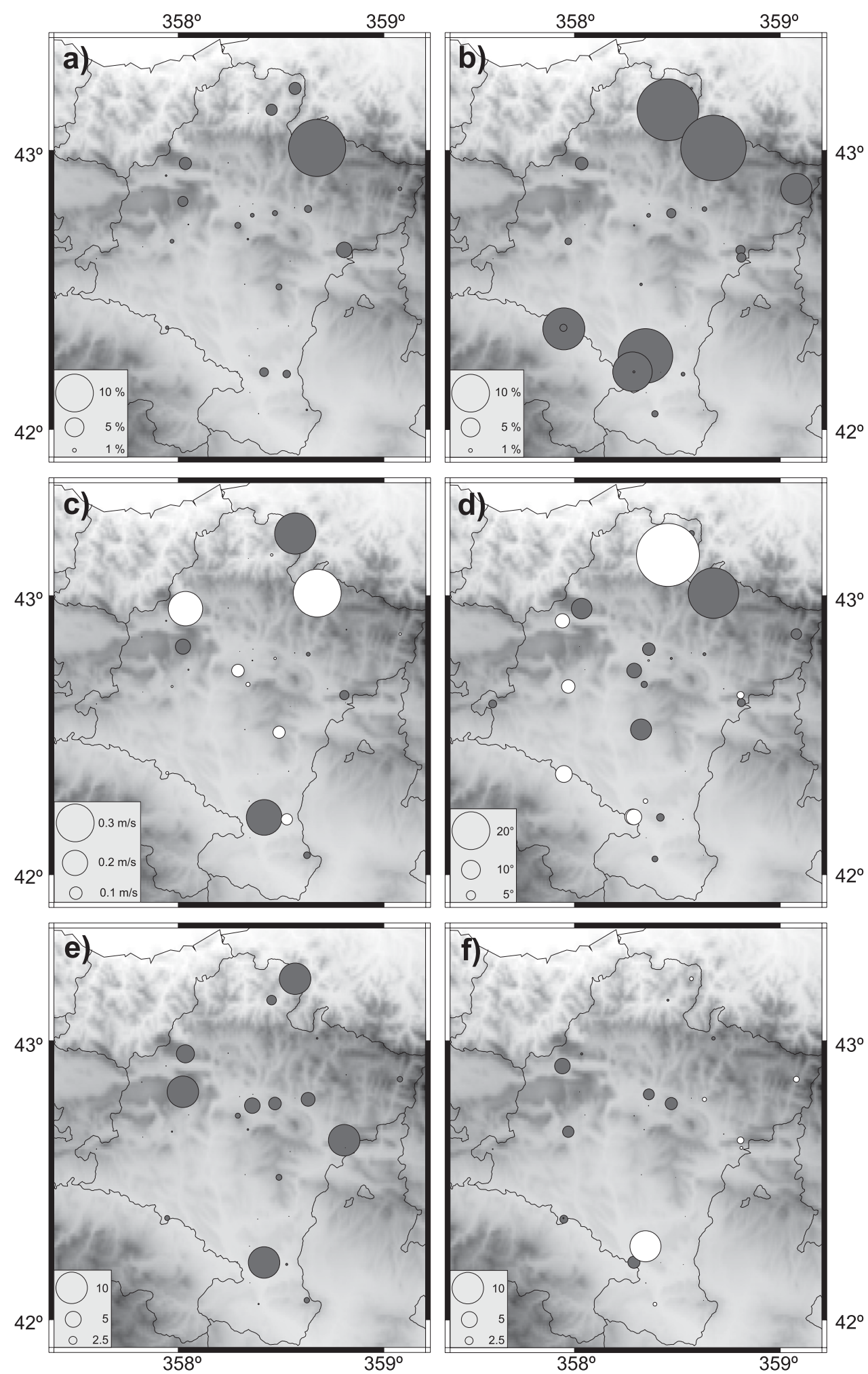

FIG. 16. Percentage of records removed from the (a) original wind speed and (b) direction time series. (c) The bias (original minus final) is displayed for the wind speed and (d) the wind direction. A negative (positive) bias is displayed in white (black). A positive (negative) wind direction bias means that the final mean wind direction is displaced counterclockwise (clockwise) with respect to the original mean. (e),(f) The ratio between the original and final standard deviations for the wind speed and wind direction time series, respectively. A ratio lower (higher) than one is displayed in white (black). 

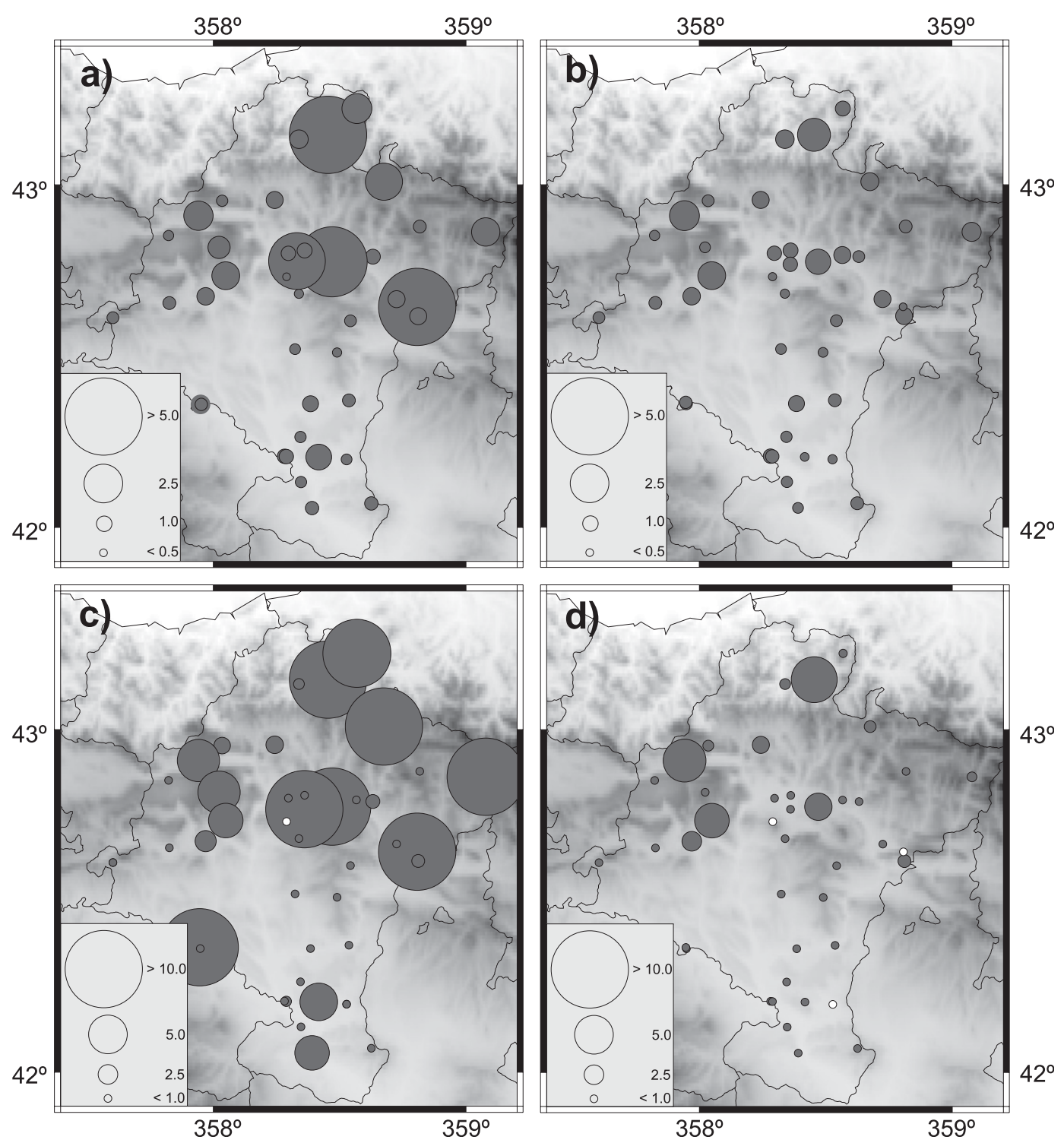

FIG. 17. Skewness of the wind speed time series (a) before and (b) after the QA. The kurtosis (c) before and (d) after the suppressions is displayed. Positive (negative) values are displayed in black (white).

of the wind speed distributions is larger in the positive direction. The kurtosis also tends to be positive, indicating a higher peak than a normal distribution at most of the sites.

\section{Conclusions}

Potential errors in the wind speed and wind direction observations from automated weather stations have been analyzed. About $1.8 \%$ wind speed and $3.7 \%$ wind direction records were assumed invalid (Table 2). The abnormally low variation is the principal cause for wind speed record invalidation, while systematic errors associated with an anomalous range of variation are the most important source of invalid wind direction measurements. Stations located at mountaintops tend to show a larger number of invalidated records probably due to the more adverse meteorological conditions at these sites.

Some of the errors detected persist over a long period of time, during which inconsistent observations are recorded. This not only affects the loss of data, but it also complicates the task of the QA. The potential loss of a high percentage of observations, as well as the considerable amount of time and effort necessary to identify and invalidate the inconsistent records, can be avoided by applying routine maintenance operations (appropriately reflected in metadata) and performing a real-time QC on the recorded data to detect anomalous behavior of the records (e.g., Shafer et al.2000). The causes that originate 
the problems detected, especially those that persist over time, should be analyzed to mitigate them and thus increase the quality of future observations.

The corrections applied have been shown to have a clear impact on the general statistics of the dataset. This underlines the importance of QA procedures, as applied here. The impacts of the corrections are small at certain locations, but this means that the observations are of good quality, which could not have been guaranteed before the application of the present depuration process. In this sense, the QA process will confer more robustness to the conclusions reached in future studies using this dataset.

The dataset has proven useful for understanding the wind variability in the area (Jiménez et al. 2008) and the relationship between large-scale and surface circulations (Jiménez et al. 2009). The complexity of the local terrain means that the dataset can be used to provide a better understanding of the ability of mesoscale numerical simulations to reproduce the surface flow over complex terrain (Jiménez et al. 2010).

It should also be pointed out that the resulting data are not expected to represent an error-free dataset, but it is one where the quality of the time series has been significantly improved. Future updates on the dataset and the testing of new methodologies will hopefully lead to new quality corrections. We are currently considering the possibility of updating the wind dataset to expand it until 2010 and are finding potential ways to improve the QA herein described. For this purpose it would be very useful to analyze the rate of records that are flagged as invalid but were actually correct, because it will us allow to quantify the efficiency of different checks.

Acknowledgments. This project was accomplished within the collaboration agreement 09/153 between UCM and CIEMAT, and it was partially funded by projects CGL2005-06966-C07/CLI and PSE-120000-2008-9. We thank the Navarra Government for providing us with the wind dataset used in this study. We also like to thank the reviewers for their helpful comments.

\section{REFERENCES}

Aguilar, E., I. Auer, M. Brunet, T. C. Peterson, and J. Weringa, 2003: Guidelines on climate metadata and homogenization. WMO Tech. Rep. WMP-TD 1186, 55 pp.

Alexanderson, H. A., 1986: A homogeneity test applied to precipitation data. J. Climatol., 6, 661-675.

Bailey, B. H., and S. L. McDonald, 1997: Wind Resource Assessment Handbook. AWS Scientific, 79 pp.

Brunet, M., and Coauthors, 2006: The development of a new dataset of Spanish Daily Adjusted Temperature (SDATS) (18502003). Int. J. Climatol., 26, 1777-1802.

DeGaetano, A. T., 1997: A quality-control routine for hourly wind observations. J. Atmos. Oceanic Technol., 14, 308-317.
_ 1998: Identification and implications of biases in U.S. surface wind observation, archival, and summarization methods. Theor. Appl. Climatol., 60, 151-162.

Della-Marta, P. M., 2006: A method for hogenizing the extremes and mean of daily temperature measurements. J. Climate, 19, 4179-4197.

Durre, I., M. J. Menne, and R. S. Vose, 2008: Strategies for evaluating quality assurance procedures. J. Appl. Meteor. Climatol., 47, 1785-1791.

Eischeid, J., C. B. Baker, T. Karl, and H. F. Díaz, 1995: The quality control of long-term climatological data using objective data analysis. J. Appl. Meteor., 34, 2787-2795.

Feng, S., Q. Hu, and W. Qian, 2004: Quality control of daily meteorological data in China, 1951-2000: A new dataset. Int. J. Climatol., 24, 853-870.

Fiebrich, C. A., D. L. Grimsley, R. A. McPherson, and K. A. Kesler, 2006: The value of routine site visits in managing and maintaining quality data from the Oklahoma Mesonet. J. Atmos. Oceanic Technol., 23, 406-416.

Filippov, V. V., 1968: Quality control procedures for meteorological data. WMO Tech. Rep., 38 pp.

Gandin, L. S., 1988: Complex quality control of meteorological observations. Mon. Wea. Rev., 116, 1137-1156.

González-Rouco, J. F., J. L. Jiménez, V. Quesada, and F. Valero, 2001: Quality control and homogeneity of precipitation data in the southwest of Europe. J. Climate, 8, 964-978.

Grant, E. L., and R. S. Leavenworth, 1972: Statistical Quality Control. McGraw-Hill, 764 pp.

Graybeal, D. Y., 2006: Relationships among daily mean and maximum wind speeds, with application to data quality assurance. Int. J. Climatol., 26, 29-43.

—, A. T. Degaetano, and K. L. Eggleston, 2004a: Complex quality assurance of historical hourly surface airways meteorological data. J. Atmos. Oceanic Technol., 21, 1156-1169.

- _ — , and — , 2004b: Improved quality assurance for historical hourly temperature and humidity: Development and application to environmental analysis. J. Appl. Meteor., 43, 1722-1735.

Hubbard, K. G., S. Goddard, W. D. Sorensen, N. Wells, and T. T. Osugi, 2005: Performance of quality assurance procedures for an applied climate information system. J. Atmos. Oceanic Technol., 22, 105-112.

— N. B. Guttman, J. You, and Z. Chen, 2007: An improved QC process for temperature in the daily cooperative weather observations. J. Atmos. Oceanic Technol., 24, 206-213.

Jiménez, P. A., J. F. González-Rouco, J. P. Montávez, J. Navarro, E. García-Bustamante, and F. Valero, 2008: Surface wind regionalization in complex terrain. J. Appl. Meteor. Climatol., 47, 308-325.

,,-- E. García-Bustamante, and J. Navarro, 2009: Climatology of wind patterns in the northeast of the Iberian Peninsula. Int. J. Climatol., 29, 501-525.

- — , E. García-Bustamante, J. Navarro, J. P. Montávez, J. Vilà-Guerau de Arellano, J. Dudhia, and A. Roldan, 2010: Surface wind regionalization over complex terrain: Evaluation and analysis of a high resolution WRF numerical simulation. J. Appl. Meteor. Climatol., 49, 268-287.

Jungo, P., S. Goyette, and M. Beniston, 2002: Daily wind gust speed probabilities over Switzerland according to three types of synoptic circulation. Int. J. Climatol., 22, 485-499.

Karl, T. R., and C. N. Williams, 1987: An approach to adjusting climatological time series for discontinuous inhomogeneities. J. Climate Appl. Meteor., 26, 1744-1763. 
P. J. Young, and W. M. Wendland, 1986: A model to estimate the time of observation bias associated with monthly mean maximum, minimum, and mean temperature for the United States. J. Climate Appl. Meteor., 25, 145-160.

— J. D. Tarpley, R. G. Quayle, H. F. Diaz, D. A. Robinson, and R. S. Bradley, 1989: The recent climate record: What it can and cannot tell us. Rev. Geophys., 27, 405-430.

Kunkel, K. E., and Coauthors, 1998: An expanded digital daily database for climatic resources applications in the midwestern United States. Bull. Amer. Meteor. Soc., 79, 1357-1366.

—, D. R. Easterling, K. Hubbard, K. Redmond, K. Andsager, M. C. Kruk, and M. L. Spinar, 2005: Quality control of pre1948 cooperative observer network data. J. Atmos. Oceanic Technol., 22, 1691-1704.

Lanzante, J. R., 1996: Resistant, robust, and nonparametric techniques for the analysis of climate data: Theory and examples, including applications to historical radiosonde station data. Int. J. Climatol., 22, 1197-1226.

Mardia, R. V., and P. E. Jupp, 1999: Directional Statistics. J. Wiley and Sons, $429 \mathrm{pp}$.

Meek, D. W., and J. L. Hatfield, 1994: Data quality checking for single station meteorological databases. Agric. For. Meteor., 69, 85-109.

Parker, D. E., T. A. Basnett, S. J. Brown, M. Gordon, E. B. Horton, and N. A. Rayner, 2000: Climate observations-The instrumental record. Space Sci. Rev., 94, 309-320.

Paulsen, B. M., and J. L. Schoeder, 2005: An examination of tropical and extratropical gust factors and the associated wind speed histograms. J. Appl. Meteor., 44, 1197-1226.

Peterson, T. C., and Coauthors, 1998a: Homogeneity adjustments of in situ atmospheric climate data: A review. Int. J. Climatol., 18, 1493-1517.

, R. Vose, R. Schmoyer, and V. Razuvaev, 1998b: Global Historical Climatology Network (GHCN) quality control of monthly temperature data. Int. J. Climatol., 18, 1169-1179.

Pielke, R., Sr., and Coauthors, 2007a: Unresolved issues with the assessment of multidecadal global land surface temperature trends. J. Geophys. Res., 112, D24S08, doi:10.1029/2006JD008229.

, and Coauthors, 2007b: Documentation of uncertainties and biases associated with surface temperature measurement sites for climate change assessment. Bull. Amer. Meteor. Soc., 88, 913-928.
Reek, T., S. R. Doty, and T. W. Owen, 1992: A deterministic approach to the validation of historical daily temperature and precipitation data from the cooperative network. Bull. Amer. Meteor. Soc., 30, 511-523.

Shafer, M. A., C. A. Fiebrich, D. S. Arndt, S. E. Fredrickson, and T. W. Hughes, 2000: Quality assurance procedures in the Oklahoma mesonetwork. J. Atmos. Oceanic Technol., 17, 474-494.

Thompson, D., J. J. Kennedy, J. M. Wallace, and P. D. Jones, 2008: A large discontinuity in the mid-twentieth century observed global-mean surface temperature. Nature, 453, 646-649.

Vejen, F., and Coauthors, 2002: Quality control of meteorological observations. Automatic methods used in the Nordic countries. KLIMA Tech. Rep. 8/2002, 106 pp.

Venables, W. N., and B. D. Ripley, 1999: Modern Applied Statistics with S-plus. 3rd ed. Springer, 501 pp.

Vincent, L. A., X. Zhang, B. R. Bonsal, and W. D. Hogg, 2002: Homogenization of daily temperatures over Canada. J. Climate, 15, 1322-1334.

Wade, C. G., 1987: A quality-control program for surface meteorological data. J. Atmos. Oceanic Technol., 4, 435-453.

Wan, H., X. X. L. Wang, and V. R. Swail, 2007: A quality assurance system for Canadian hourly pressure data. J. Appl. Meteor. Climatol., 46, 1804-1817.

Weggel, J. R., 1999: Maximum daily wind gusts related to mean daily wind speed. J. Struct. Eng., 125, 465-468.

Wijngaard, J. B., A. M. Klein Tank, and G. P. Können, 2003: Homogeneity of 20th century European daily temperature and precipitation series. Int. J. Climatol., 23, 679-692.

WMO, 2008: Guide to meteorological instruments and methods of observation. Tech. Rep. WMO 8, 679 pp.

Wu, H., K. G. Hubbard, and J. You, 2005: Some concerns when using data from the cooperative weather station networks: A Nebraska case study. J. Atmos. Oceanic Technol., 22, 592-602.

Xoplaki, E., J. F. González-Rouco, J. Luterbacher, and H. Wanner, 2004: Wet season Mediterranean precipitation variability: Influence of large-scale dynamics and predictability. Climate Dyn., 23, 63-78.

You, J., K. G. Hubbard, S. Nadarajah, and K. Kunkel, 2007: Performance of quality assurance procedures on daily precipitation. J. Atmos. Oceanic Technol., 24, 821-834. 